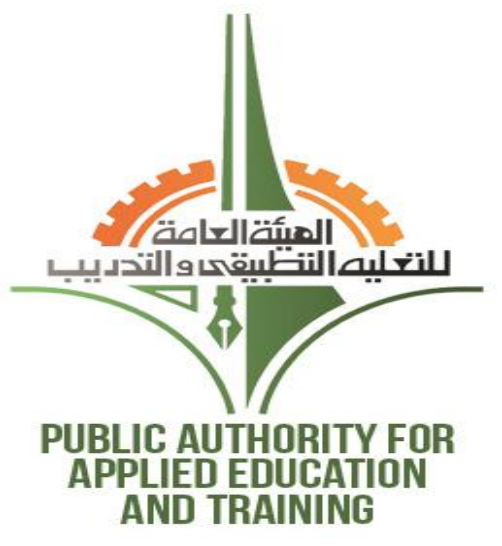

أثز القيادة التحويلية على متطلبات تطبيق إدارة المعرفة بمنظمات التعليم التطبيقى

دراسة من وجهة نظر السادة المدربين بمعهد السكرتارية والإدارة المكتبية بالهيئة العامة للتعليم

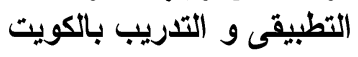

\author{
إعداد \\ عفاف مرشد محمد المرشد \\ مدرب متخصص ج بمعهد السكرتارية والإدارة المكتبية \\ بالهيئة العامة للتعلين التطبيقى والتدريب بالكويت
}




\section{أثر القيادة التحويلية على متطلبات تطبيق إدارة المعرفة}

دراسة من وجهة نظر السادة المدربين بمعهل السكرتارية والإدارة المكتبية بالهيئة العامة للتعليم التطبيقى و التدريب بالكويت

مقدمة

يحظى موضوع إدارة المعرفة فى الوقت الراهن باهتمام مثزايد لاى كثير من

الباحثين ، فقد أصبح من أكثر الموضوعات حيوية فى الفكر الإدارى المعاصر ، و إدارة المعرفة أحد المفاهيم الإدارية المعاصرة ، وخلال العقدين الماضيين شهدت إدارة

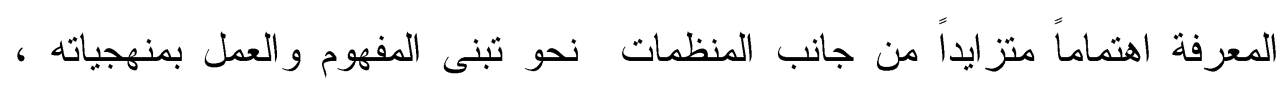

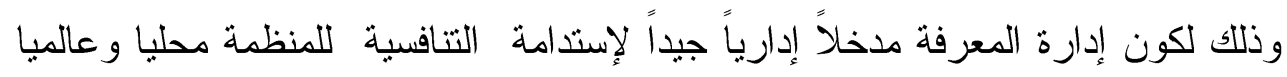

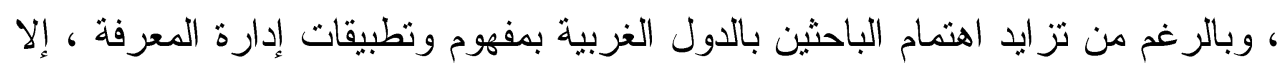

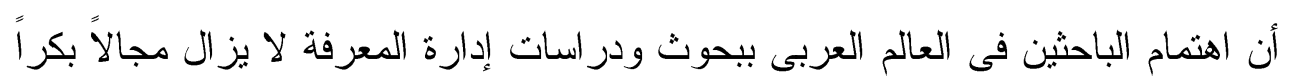
للبحوث و الدراسات العلمية ، بل ماز ال بعيد إلى حد ما عن تصور الكثير من المديرين العرب بالرغم من أهميته ودلالاته المفيدة لمجتمعنا الخليجى لما يتوفر له من امكانات تجعل له السبق فى ريادة المنظمات بمختلف أنو اعها عربيا وعالميا .

و تلعب التحديات المعاصرة التى تواجها المنظمات دوراً كبيراً فى إبراز الأهمية المتز ايدة لإدارة المعرفة ، وهذا بدوره يكسب إدارة المعرفة أهمية في ظل تلك

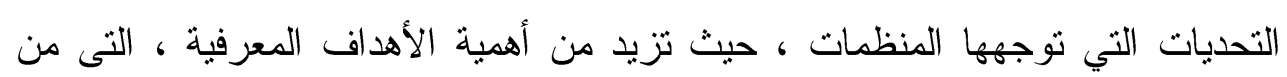

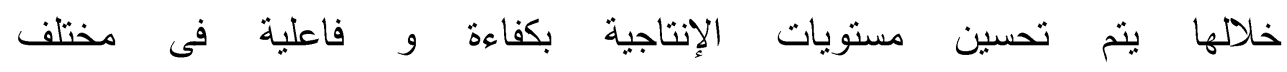
. المنظمات و يمكن تحقيق الفائدة المرجوة من مدخل إدارة المعرفة في المنظمات ، من خلال دور إدارة المنظمة فى تفعيل مدخل إدارة المعرفة وتوظبفه فى إطار تحقيق الأهداف الاستر اتيجية و التشغيلية للمنظمات، وتعزيز قدرات المنظمة ومهار ات كو ادرها 
، وتحقيق النطوير و التحسين و الاستدامة لهذه القدرات و المهارات ، و ثوظيف عمليات إدارة المعرفة نحو تحقيق المعرفة فى كل وحدة من الوحدات بالمنظمة .

ويعثبر العنصر البشرى من المجالات الحيوية التى يجب أن يهتم بها القادة فى

المنظمات ، و على القادة تأهيل قادة المستقبل لتحقيق رؤية ورسالة وأهداف منظماتهج ، فمن خلا ذللك يستطيعون بث روح الإبتكار بين مرؤسيهم والإسهام فى إعداد جيل من القادة القادرين على قدح شرارة الإثارة فى العمل وتحدى المشكلات و تحقيق رضا جميع الأطر اف عاملين و متعاملين و إدارة عليا(i) .

فالمنظمات بمختلف أنُكالها و أهدافها و أحجامها، و المداخل المسخدمة في إدارتها ، تتضمن أفر اد منظمين في شكل قانونى ، و شروط و اقعية معينة تفرض القيام بمهام محددة تهدف في مجموعها إلى تحقيق غايات و أهداف ، و من ثم تتحقق الغايات و الأهداف عن طريق الاهنمام بمجموع الموارد الموجودة داخل المنظمة سواء موارد مالية أو تقنية أو بشرية ، و الموارد البشرية تعتبر المورد الفعال من بين الموارد المختلفة في المؤسسة بمختلف مستوياتها ، ومن أهم المواضيع المرتبطة بالمورد البشري في

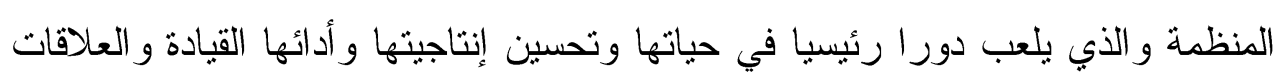
الإشر افية ، فالقيادة من العو امل المؤثرة في إدارة المعرفة حيث دورها فى ثلبية الحاجات اليومية للعاملين والمنظمة ككل من خلال الاتصال و العلاقات الإنسانية المتميزة بالديناميكية فى التعامل وضمان حد من التنسيق بين كل الوظائف و المستويات التنظيمية وتدعيم المشاركة التنظيمية فى كل المجالات وتشجيع روح التعاون قصد تحقيق أهداف

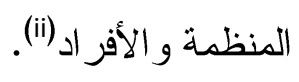

قإن نجاح المنظمات الحديثة يتطلب إستخدام نمط إدارى وقيادى يؤمن بضرورة التكيف والنطور المستمر ومشاركة الجميع فى الرؤية الآنية و المستقلية و العمل على لئ تحويلها إلى واقع ملموس للتمكن من نقل المنظمة للوضع المنشود بطريقة هادفة ومنظمة(iii) ، وفى هذا الإطار تسعى القيادة التحويلية الــى تطـــوير وتشجيع المرؤوسين 
فكرياً وابداعياً وتحول اهتماماتهر من المصالح الذاتية الآنية إلى اهتمامات خاصة بالإنجاز و التقدم و النتمية الذاتبة لتكون جزء أساسى فى الرسالة العليا للمنظمة (iv) .

\section{مشكلة الار اسة}

لا تكاد توجد منظمة أى كانت لا تطمح إلى تحقيق النمو والتقدم و انجاز الأهداف

، و الوصول الى أهدافها المستقبلية ، ويتحقق ذلك من خلال الممارسة العلمية و التأهيل و التنريب ، وتلعب القيادة التحويلية دور الهاما فى تحقيق و إدارة المعرفة فيما يتعلق ببناء قدر ات العاملين و اكتشافهم و استثمار هم فى تحليل مشكلات منظماتهر ، وذلك باعتبار أن القبادة التحويلية تتمثل فى القدرة على مو اعمة الوسائل مع الغايات وتتكيل و إعادة تشكيل المؤسسات لتحقيق أغر اض إنسانية عظيمة وتطلعات أخلاقية ، حيث يقوم هذا النمط القيادى على إدرالك الحاجات الظاهرة و الكامنة للمرؤسيين و العمل على إثباع تلك الحاجات واستثمار أقصى طاقات المرؤسيين بهدف تحقيق تغيير مقصود ، ليس فقط بل ليل

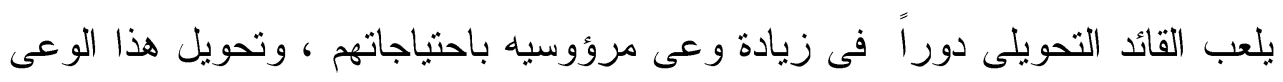
بالإحتياجات إلى آمال وتوقعات ، ومن ثم الإرتقاء بمستوى مرؤوسيه نحو الإنجاز و النظوير الذاتى ونمو وتطور المنظمة .

وبناءاً على ماسبق كان هناك ايماناً من الباحثة بعمق قضية إدارة المعرفة

وتفعيلها من أجل كويتتا العظيم وللوصول بمنظمتا إلى أعلى درجات التتافسية الإقليمية و العالمية تمشيا مع توجيهات القيادة الرشيدة لدولة الكويت ، وذلك من خلال ربط إدارة المعرفة بأحد المفاهيم الحديثة فى علوم الإدارة وهى القبادة التحويلية حيث أمكن للباحثة صياغة موضوع بحثها فى تساؤل بحثى رئيس هو "ما أثر القيادة التحويلية على إدارة

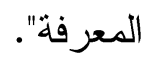




\section{أهمية الار اسة}

1- تستمد الدراسة أهميتها العلمية من أهمية محاورها الرئيسية فكون موضوع إدارة المعرفة

و القيادة التحويلية موضعان حظى وماز ال يحظيا باهتمام وشغف بالغ من قبل الباحثين ، حيث أن تقدم المجتمعات وتطور منظماتها و استدامة التقام و التطور يعتمد بشكل أساسى على نوع القيادات التى تحركها وترسم خططها وعلى مدى ما تتتجه منظماتهم من

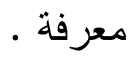

r- تبرز الأهمية التطبيقية لهذه الدراسة فى محاولة التوصل إلى مجموعة من المؤشرات يعتمد عليها كدليل عمل للوصول بالمنظمات لتفعيل إدارة المعرفة و يمكن تعميمه تطبيقيا على المنظمات بدولة الكويت . r- هذه النوعية من الدر اسات تسهم فى حث القيادات الإدارية على توظيف ما لديها من خصائص لأن يكونو ا قادة تحوليون فى مجال إدارة المعرفة بمنظماتهر • ع- يعتبر موضوع القيادة التحويلية وعلاقتها بإدارة المعرفة ماز ال من الموضوعات حديثة التتاول بمجنمعنا العربى بصفة عامة ، ومحدودة التناول فى حدود علم الباحثة فى المجال التعليمى و الثدريبى على وجه الخصوص ، مما يجعل من كونه موضو عا جدير بالدر اسة

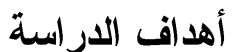

يتمثل الهدف الرئبسى للار اسة فى التعرف على آثز القبادة التحويلية فى تفعيل منطلبات تطبيق إدارة المعرفة و المنمثلة فى ( التقافة التنظيمية ـ القيادة التنظيمية ـ الموارد البشرية - تكنولوجيا المعلومات ) و ذلك من وجهة نظر السادة المدربين بمعهز السكرنارية و الإدارة المكتبية بالهيئة العامة للنعليم النطبيقى و التذريب وينبثق من هذا الهذف العام مجموعة من الأهداف الفرعية على النحو التالى :- 
ا- التعرف على آثز القيادة التحويلية على بعد الثقافة التنظيمية كأحد متطلبات تطبيق إدارة المعرفة.

ץ- التعرف على آثر القيادة التحويلية على بعد القيادة التنظيمية كأحد منطلبات تطبيق إدارة المعرفة.

ب- التعرف على آثز القيادة التحويلية على بعد الموارد البشرية كأحد متطلبات تطبيق إدارة

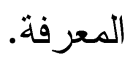

ع- التعرف على آثز القيادة التحويلية على بعد تكنولوجيا المعلومات كأحد منطلبات تطبيق إدارة المعرفة . - مارة

\section{فروض الار اسة}

يتمثل الفرض الرئيسى للار اسة فى أنه توجد علاقة ايجابية بين القيادة التحويلية و

منطلبات تطبيق إدارة المعرفة و المتمثلة فى ( الثقافة التنظيمية - القيادة التنظيمية ـ الموارد البشرية ـ تكنولوجيا المعلومات ) ، و ذلك من وجهة نظر السادة المدربين بمعهد السكرتارية و الإدارة المكتبية بالهيئة العامة للتعليم التطبيقى و التنريب وينبثق من هذا الفرض العام مجموعة من الفروض الفرعية على النحو التالى :-

1- توجد علاقة ايجابية ذات أثز بين القيادة التحويلية و بعد الثقافة التنظيمية كأحد متطلبات

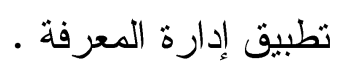

ץ- توجد علاقة ايجابية ذات أثز بين القيادة التحويلية و بعد القيادة التنظيمية كأحد متطلبات

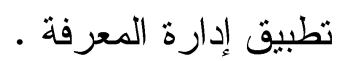
r- توجد علاقة ايجابية ذات أثر بين القيادة التحويلية و بعد الموارد البشرية كأحد منطلبات تطبيق إدارة المعرفة . ع- توجد علاقة ايجابية ذات أثز بين القيادة التحويلية و بعد تكنولوجيا المعلومات كأحد منطلبات تطبيق إدارة المعرفة . 


\section{الار اسات السابقة}

لقد تناولت العديد من الدراسات موضوع القبادة التحويلية وعلاقتها بالإبداع الإدارى ، و التى استطاعت الباحثة الحصول عليها ذات العلاقة بمتغيرات الدراسة و من

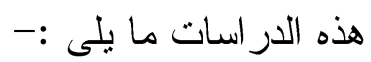

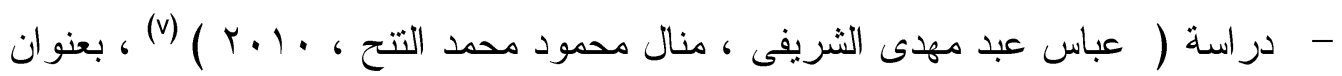
درجة ممارسة مديرى المدارس الثانوية الخاصة فى دولة الإمارات العربية المتحدة للقبادة التحويلية من وجهة نظر معليمهم ، استهدفت الدراسة التعرف على مدى ممارسة القيادة التحويلية ، ، و واستخدت الباحثة استبانة القيادة متعددة العو امل لقباس درجة ممارسة القيادة التحويلية ، وقد توصلت الدراسة إلى أن درجة ممارسة مديرى المدارس الثانوية الخاصة فى دولة الإمارات العربية المتحدة للقيادة التحويلية بشكل عام كانت مرتفعة من وجهة نظر المعلمين و المعلمات .

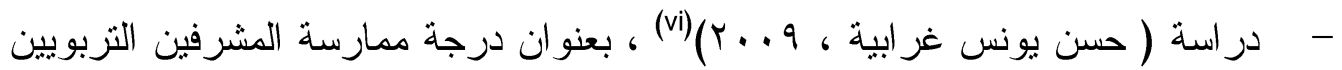
لسلوك القيادة التحويلية وعلاقتها بمستوى آدائهم ، حيث استهدفت التعرف الى درجة ممارسة المشرفين التزبويين لسلوك القيادة التحويلية وعلاقتها بمستوى أدائهم من وجهة نظر المعلمين وتم اختبار عينة طبقية عنقودية عشوائية بلغ عدد افر ادها (. .ع) معلماً ومعلمة ، ولتحقيق أهداف الدراسة إستخدم الباحث قياس السلوك التحويلي لقياس درجة ممارسة المشرفين التربويين للقيادة التحويلية ومقياس الآداء الإشر افى لقياس مستوى آداء المشرفين التربويين ، و المقابلات الفردية لعينة عشو ائية بلغ عددها (·r) معلما ومعلمة من مديريات اربد الأولى و المفرق و الرمثا ، وتمثلت أهم نتائج الدراسة ان ممارسة المشرفين التربويين لسلوك القيادة التحويلية كان بدرجة متوسطه ، كما كان درجة آداء المشرفين التزبويين أيضا بدرجة منوسطه ، كما أوضحت النتائج أن المشرفون التزبويون يمارسون نموذج كريزماتى في التأثثر على المعلمين الذكور بدرجة عالية . 


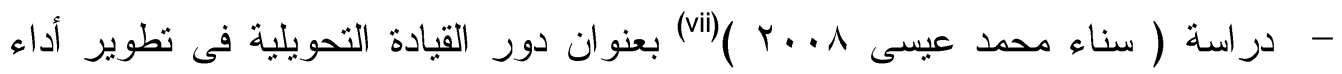
مديرى الددارس الثانوية فى محافظات غزة ، حيث هدفت الدراسة التعرف على دور القيادة النحويلية فى تطوير آداء مديرى المدارس الثانوية وواقع ممارستهم للقيادة النحويلية وسبل تطوير آدائهم ، اعتمد الباحثة على المنهج الوصفى ، و قد أكدت

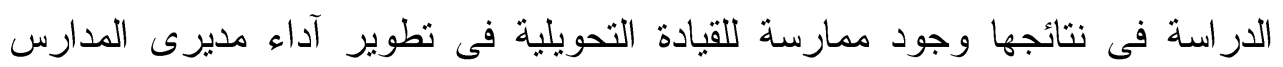

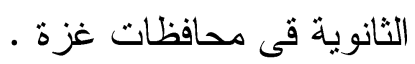

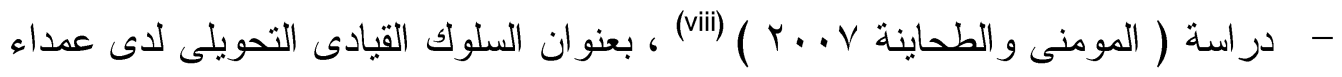

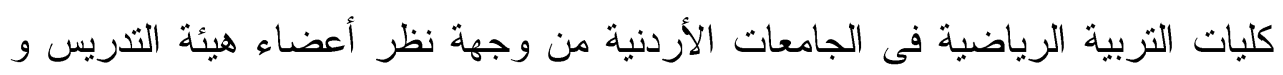
علاقتها برضائهم الوظيفى ، وقد استهدفت الدراسة التعرف على أنماط السلوك القيادي

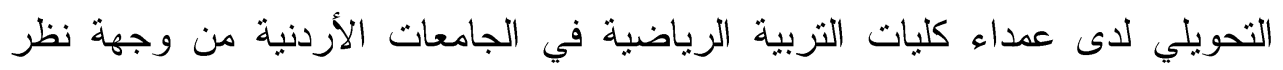

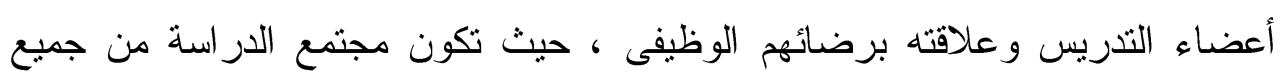
أهضاء هيئة التنريس ومساعدي البحث العاملين في كليات التربية الرياضية في

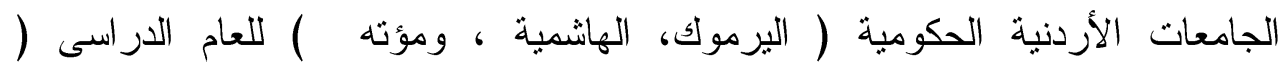

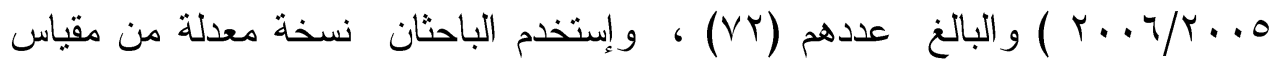
القيادة متعدد العوامل ، وقد أظهرت الننائج أن رضا أعضاء الهيئة الندريسية عن عملهم كان متوسطا و أن عمداء كليات التربية الرياضية يمارسون القيادة التحويلية بدرجة متوسطة ، كما أظهرت النتائج أن السلوك القيادي التحويلي بأبعاده المختلفة يؤثر في

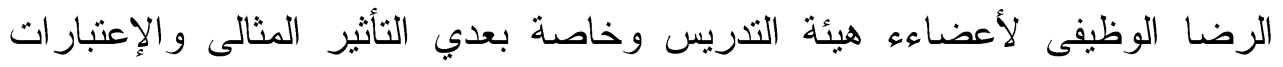

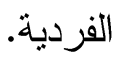

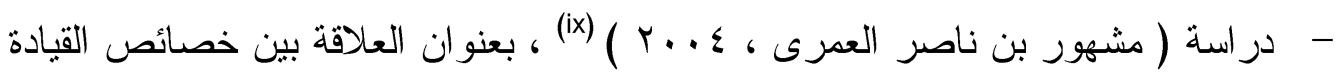

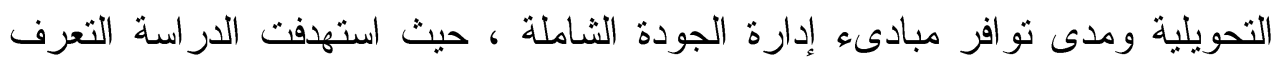
على العلاقة بين خصائص القبادة التحويلية ومدى تو افر مبادى إدارة الجودة الشاملة ، و اعتمد الياحث على استبانة مستخدما المنهج الوصفى النحليلى ، وقد توصلت الدراسة 
إلى أن مستوى القيادة التحويلية للمديرين فى المؤسسات قيد الدراسة لا يرقى إلى المستوى المأمول ، كما أنضح أن هناك علاقة إيجابية قوية ذات دلالة إحصائية بين خصائص القيادة التحويلية إجمالاً تزتبط بعلاقات إيجابية بإدارة الجودة بشكل عام .

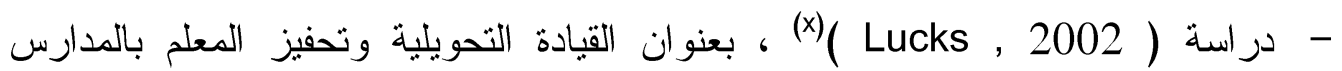
الثانوية بنيويورك ، حيث استهدفت الدراسة الوقوف على طبيعة العلاقة بين القيادة التحويلية وبين دافعية المعلمين ، وشملت الدر اسة ( • • ( ) مدرسة بنيويورك و استخدمت مقياس لقياس أنماط القيادة المتبعة لدى الإدارة المدرسية وأداة لمسح الرضا الوظيفى ، وقد اتضح أنه لا توجد علاقة تبرهن على أن القيادة التحويلية ذات آثر على دافعية المعلمين بمدارس مدينة نيويورك ، كما أوضحت الدراسة أن القائد التحويلى لا يختلف مع غيره من القادة الذين بستخدمون أنماط أخرى من القيادة فى التأثير على دافعية المعلمين -

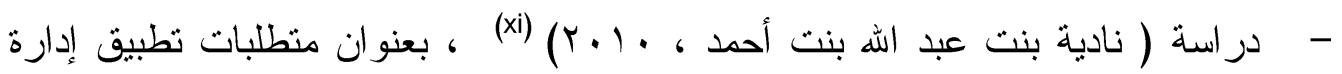
المعرفة فى جامعة السلطان قابوس ، هدفت الدراسة إلى التعرف على الأسس النظرية و الفكرية لإدارة المعرفة ، و التعرف على درجة تو افر منطلبات تطبيق إدارة المعرفة في جامعة السلطان قابوس من وجهة نظر أعضاء هيئة التنريس بكلبات الجامعة ، وقامت الباحثة بتصميم استبانة مكونة من ستة محاور ، كما شملت عينة الدراسة (ع ا ا) عضو هيئة تدريس من كليات الجامعة ، وتمثلت أهم النتائج التي توصلت إليها الدراسة أن درجة تو افر متطلبات تطبيق إدارة المعرفة في جامعة السلطان قابوس كانت منوسطة في كل محاور الدراسة عدا محور أعضاء هيئة الندريس الذي حصل على درجة توافر كبيرة ، أما فيما يتعلق بمتغيرات الدراسة فقد توصلت نتائج الدراسة إلى عدم وجود فروق ذات دلالة إحصائية بين متوسطات تقديرات أفر اد العينة على محاور الدراسة تعزى إلى منغير النوع و سنو ات الخبرة ، بينما وجدت فروق ذات دلالة إحصائية عند مستوى دلالة بين متوسطات تقديرات أفراد العينة تعزى إلى متغير نوع الكلية لصالح 
الكليات العلمية على محور أعضاء هيئة التذريس ، ولصالح كليات العلوم الإنسانية على محور التكنولوجيا ،وخلصت الدراسة إلى قائمة منطلبات مقترحة لتطبيق إدارة المعرفة في جامعة السلطان قابوس •

\section{التعقيب على الدراسات السابقة}

بعد استعر اض الدراسات السابقة نجد أن غالبيتها نفذت فى قطاعات مخالفة لموضوع الدراسة الر اهنة وهو قطاع التعليم التطبيقى و التدريب ، وتركز الدراسة الر اهنة على البيئة الكويتية بهدف تطويرها وتطوير العاملين و الدراسين بقطاع التعليم النطبيقى والتدريب وحثهم على الابداع المستمر الذى يسمو بالهيئة وقد hستفادت الباحثة من الدراسات السابقة فى تحديد منهجية البحث وصباغة الأهداف و استتباط فروض

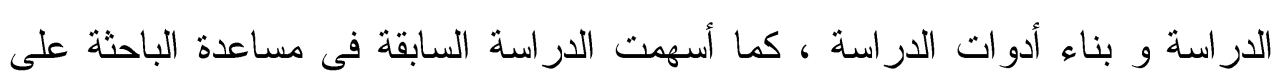
إنتقاء الأساليب الإحصائية المناسبة

\section{معطيات الدراسة النظرية}

\section{القيادة التحويلية}

يعرف ( الخطيب و آخرون ، 1991 ) القيادة التحويلية بأنها قدرة تأثير شخص ما على الآخرين حيث يقبلون قيادته طو اعية ، بغير إلزام قانونى ، وذلك إيماناً منهم بقيمة

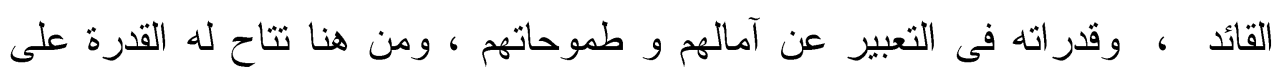
القيادة وكسب تعاون العاملين معه ، مما يمنحه القدرة على إقناع المرؤسين بأن تحقيقهم لأهداف التنظيم يعد نجاحاً شخصياً لهم وتحقيقاً لأهدافهم (xii) .

فالقيادة التحويلية أحد المداخل الحديثة التى تؤدى بالقادة و المرؤسين العمل بأقصى قدر اتهم لتفعيل آدائهم ، وتلبية احتياجاتهم الاجتماعية و المعنوية ، من أجل مزيد من الثقة بالنفس لإنتاج خدمات أو السلع بأعلى كفاءة (xiii) . 
وتلعب القيادة النحويلية دوراً محوريا لا غنى عنه في إحداث التغييرات التنظيمية المناسبة لتحقيق الأهداف التنظيمية خلال سعي القائد الى تحسين آداءالمرؤسين ، كما تعمل القيادة التحويلية على التتمية المهنية و الذاتية للعاملين و التنظيم (xiv) . وقد شهدت نظورات نظرية القبادة تحول الاهتمامات من نظرية القيادة الكارزمية إلى النظرية الكارزمية المحدثة ، ثم إلى نظرية القبادة التحويلية التي تهنم بالسمات الاجتماعية للقائد فى قيادة مرؤسيه وليس قيادة ما يمكلون من سمات شخصية ، كما أنها تهنم بتتمية واتاحة المناخ التنظيمى على الآداء بصورة أكثر استقلالاً ، ومن ثم أصبحت القبادة التحويلية أكثر شمو لاً وعمقا من القيادة الكارزمية (xv) .

و تعنى نظرية القيادة التحويلية نظرية قيادة المدى الثاملة ، وهى تعمل على تحديث مدلو لاتها من أجل فهم منكامل للقبادة التحويلية و التى يعبر عنها فى أدبيات القبادة

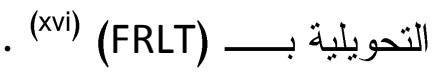

و لسلوك القيادة فى إطار القياد التحويلية ثلاث أبعاد رئيسية فعالية أولها نأثير القائد ، ثم نوع أنشطة وأساليب العمل ، بجانب الثبات الإنفعالى في التعامل مع جميع المرؤسيين بشكل ومتساوي وله درجة عالية من الثبات ، و لا شك أن ذلك يعثمد على نشاط القائد التحويلى ، و على ذللك فالقيادة التحويلية نسمى بالقيادة المبنية على النقافات ، وعموماً تطرح القيادة المعاصرة ثلاثة انو اع رئيسية ومختلفة من القادة وهي:

$$
\text { r- ا- القائد التحويلي التبادلي }
$$

r- (xvii) - (القائد السلبي او المحايد. 


\section{بعض تعريفات القيادة التحويلية}

يعرف شبرى ( Shibru : 2011 ) القيادة التحويلية بأنها احد الأنماط القيادية التى تجعل المرؤسسين بدافع من داخلهم يتجاوزون المصالح الشخصية ، ويجعلونها تتجه لصالح المنظمة ، وتجعل منهم قادة قادرين على الثنأثير فى مرؤسيهم (xviii). بينما يعرفها بيل ( Bell : 2013 ) بأنها عملية تدعم تعزيز قدرات المرؤسين للعمل من أجل أنجاز العمل الفريقى بالمنظمة تغليباً لمصالحهم الشخصية (xix).

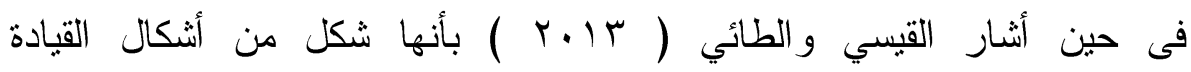

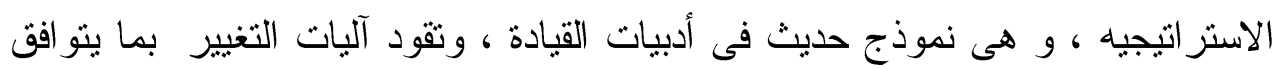

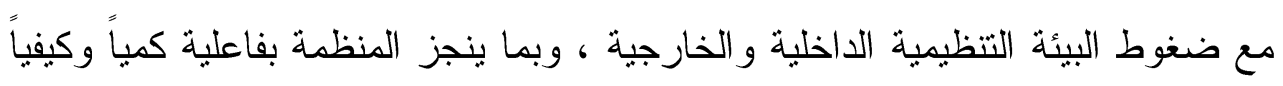

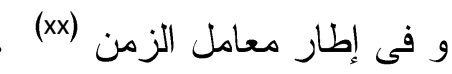

ويشير السوداني ( ع ( ب ) للقيادة التحويلية بوصفها نمط قيادي قادر على التأير في المرؤسين من حيث تحفيزهم على أداء العمل بجودة جيدة فى إطار أهداف المنظمة

ووفق مناخها التنظيمى(xxi) . ب- سمات القائد التحويلي

هناك وجهات نظر متعددة فى أدبيات نظرية القيادة حول سمات القائد التحويلى ، و أجمع غالبية المتخصصين على خمسة سمات أساسية هى:

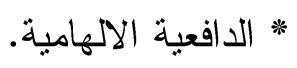

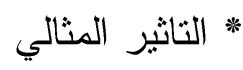

* الاعتبارية الفردية. * الاستثارة الفكرية * النمكين. وفيما ياتي توضيح هذه السمات: 
التاثير المثالى : حيث يصبح القائد التحويلى نموذجاً يحتذى به ، و لايتو انى المرؤسين فى السعى نحو إنجاز أهداف المنظمة ، كما أنهم سوف تزبطهم تفاعلات تتظيمية ذات مستويات عالية من السلوك الاخلاقى (xxii) . الدافعية الالهامية : قدرة القائد التحويلى على إثناعة روح عمل الفريق و قدرته على تحفيز المرؤسين و إلهامهم نحو التفكير فى رؤية مستقبلية و تشجيعهم على دراسة البدائل

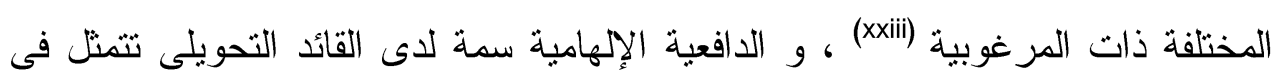
قدرته على التعبير بصورة تلقى المزيد من الاستحسان و القبول لدى المرؤسين بل تزيد من روح الحماس لديهم ، و نوجه دو افعهم نحو تحقيق الاهداف (xxiv) ، كما أن تحفيز المروؤسين برنكز فى المقام الأول على تصرف وسلوك القائد التحويلى ، كما أيضاً يسهم تحفيز المرؤسين فى جعل تأسيس مناخ تتظيمى أعضاؤه محبين للتحدى ، و اثارة المشاعر و العو اطف لدى العاملين (xxv).

الاستثارة الفكرية : وتعنى قدرة القائد على البحث عن الافكار الجديدة ، وتحفيز وتشجيع العاملين على حل و مو اجهة المشاكل بطرق ابداعية ، وكذلك دعم الاتجاهات الحديثة في طرق العمل ، و أيضاً القدرة على تتمية الوعى لدى مرؤسيه و تشجيعهم على ثبني طرق جديدة في العمل وتتاول المواقف القديمة برؤية ووجهة نظر حديثة تواكب النطور ات المعاصرة جxvi). الاعتبارية الفردية : وتتضمن قدرة القائد التحويلى بالاهنمام والرعاية لاتباعه ، كما أنه

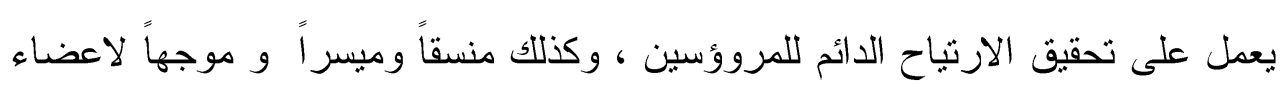
- الفريث (xxvii)

التمكين : يعتبر التمكين سلوك أصيل لدى القادة التحوليين ، وخاصة فيما يتعلق بسلطة

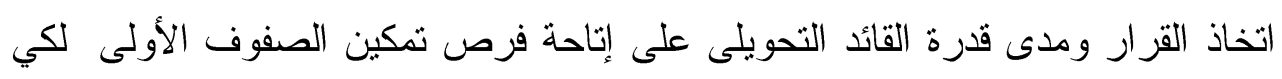
يتم تمكينهم للاستجابة بصورة ايجابية وفقاً لإحتياجات المجتمع ومشكلاتهم واحتياجاتهم (xxvii). 
تعرف إدارة المعرفة بأنها "العمليات و النشاطات النى تساعد المنظمة على توليد و الحصول على المعرفة من حيث اختيارها ، تتظيمها واستخر اجها ونشرها وتحويل المعلومات و الخبرات التى تملكها المنظمة وتوظيفها فى أنشطتها الإدارية المختلفة كإتخاذ القر ار ات و إجر اءات العمل و التخطيط الاستر اتيجى (xxix) .

يعرف ( الشيمى ، 9 . . ب ) إ"دارة المعرفة بأنها الإدارة النظامية و الو اضحة للمعرفة والعمليات المرتبطة بها و الخاصة باستحداثها وجمعها وتتظيمها ونشرها و واستخدامها و استغلالها وهى تتطلب تحويل المعرفة الشخصية إلى معرفة تعاونية يمكن تقاسمها بشكل كلى من خلال المنظمة"(xxx) .

أما (السكارنة، و . . ب) فيعرف إدارة المعرفة على أنها :حصر المعرفة من مصادرها الداخلية والخارجية وخزنها و نوزيعها و المشاركة فيها بين الأفراد لخلق معرفة جديدة وتطبيقها فى الأنشطة الإدارية "(xxii).

فإدارة المعرفة هى تخطيط وتنظيم ورقابة وتتسيق وتركيب المعرفة وما يرتبط بها من أصول مرتكزة على رأس المال الفكري ، و العمليات والقرر ات و الامكانات الثخصبة والتنظيمية ، وهى تلعب دور النأثير الايجابي لتحقيق نتائج الميزة التتافسية ، وكذلك تحقيق عملية الإستدامة للمعرفة ولر أس المال الفكرى ، و استثمار ها ونشرها، كما أنها تؤدي إلى توفير التسهيلات اللازمة لتحقيق مضامين هذه الإدارة. (xxxii) .

ومما لاشكك أن هناك إختلاف بين إدارة المعرفة ، و إدارة المعلومات فإدارة المعلومات ثرتبط بالنعامل مع البيانات و المعلومات ، و وإلى ما غبر ذلك من وثائق و تصميمات محوسبة ، بجانب الجداول الالكترونية وتخزين ونقل البيانات و المعلومات وتوفير أمن البيانات و المعلومات وجميع الوظائف والعمليات التي تتعلق بالبيانات و المعلومات ، بينما إدارة المعرفة ترتكز على تحليل المعلومات والاهنمام بتحليل 
بأصولها المعرفية ، و إدارة العمليات المتعلقة بها، وبتطوير المعرفة و الحفاظ عليها، و استخدامها و المشاركة فيها، وتتضمن الأصول المعرفية المتعلقة بالسوف والمنتجات (xxxiii)

\section{أهمية إدارة المعرفة}

تتبع أهمية إدارة المعرفة من طبيعة التأثيرات الإيجابية على المنظمات وعلى مستويات مختلفة سو اء الأفر اد أو العمليات أو المنتجات أو الآداء التنظيمى ويمكن إجمال

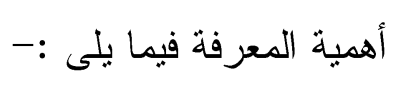

- - استثمار رأس المال الفكرى بالمنظمة . - تتسيق الأنشطة المختلفة بهدف تحقيق أنشطتها وأهدافها. - تعزيز القدر ات و الجدار ات الجوهرية فى المنظمة(xxiv) . - - تحسين الآداء التنظيمى ، حيث تعمل إدارة المعرفة على توليد معرفة جديدة وتطبيقها مما يؤدى إلى الإرتقاء بالآداء التنظيمى • - - إتاحة الفرصة لتحديد أصول المنظمة غير الملموسة وثوثيقها وتطويرها وتحديد المعرفة

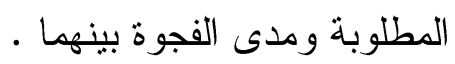
- - تحفيز المنظمات على تشجيع نشر الابتكار و الإبداع لدى مواردها البشرية لتكوين معرفة جديدة وتجديد ذاتها ومواجهة التغير ات البيئية غير المستقرة(xxxv) . - بناء ميزة تنافسية مستدامة للمنظمات . - - تحسين العمليات فى المنظمة و زيادة فاعليتها و واتخاذ القزارات المناسبة وزيادة درجة

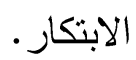

- - تحسين المنتجات الموجودة وتطويرها ولإيجاد منتجات جديدة ذات قيمة مضافة ومنتجات تعتمد على المعرفة مما يساعد فى زيادة منافسة المنظمة(xxxv) 


\section{أهداف إدارة المعرفة}

تتتوع إدارة المعرفة باختلاف وتتوع الجهات و المجالات التى توجد بها و تعمل فيها، وهنالك مجموعة من الأهداف العامة التي تشترك فيها إدارة المعرفة في مختلف أنواع

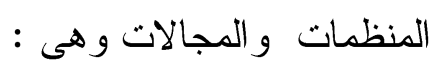

1- تحديد وجمع المعرفة وتوفير ها بالثكل و السرعة المناسبة لإستخدمها فى الوقت المناسب ، وبناء قو اعد معلومات لتخزين المعرفة وتوفير ها واسترجعها عند الحاجة إليها . r- تسهيل عمليات ثبادل ومشاركة المعرفة بين العاملين فى التتظيم • ب- تحويل المعرفة الداخلية والخارجية إلى معرفة يمكن توظيفها واستثمارها فى عمليات و أنشطة المنظمة المختلفة(xxxii) .

ع- - توفير المعلومات بشكل يساعد على تحسين عملية صنع القرار ، لتحقيق أفضل النتائج • ه- الإسهام فى حل المشكلات التى تواجه المنظمة ، و التى قد تؤدى إلى نقص كفاهتها أو هدر أمو الها ووقتها ، وتوظيف المعرفة فى حل المشكلات و التخطيط الإستر اتيجى . צ- تطوير عمليات الابتكار بالمنظمة ، وتطوير خدمات ومنتجات مبتكرة باستمر ار . -V العمل بروح الفريق ، وتحقيق التفاعل الايجابى بين مجموعات العمل . 1- نهيئة بيئة تنظيمية مشجعة وداعمة لتقافة النعلم والنظوير الذاتى المستمر • 9- الإسهام فى تسريع عمليات التطوير بالمنظمة لتلبية منطلبات التكيف مع التغيير السريع فى البيئة المحيطة بالمنظمة (xxxviii) .

\section{أبعاد إدارة المعرفة}

اتفقت معظم الكتابات على أن أبعاد إدارة المعرفة تتمثل فى الأتى :-

البعد التكنولوجي : ويتضمن المحركات البحثية الحاسوبية ، والمنتجات البرمجية ، وقو اعد بيانات ، وقو اعد الذكاءات المتعددة ، ولاشك أن إمتلاك المنظمة للبعد التكنولوجي للمعرفة يجعلها نسعى نحو كل من التميز المؤسسى و التنافسية . 
البعد التنظيمي و اللوجستي للمعرفة : بمعنى كيفية الحصول على المعرفة و التحكم بها من خلال إدارتها وتخزينها ونشرها ، وكذلك إنتاجها و إعادة استخدامها . البعد الاجتماعي : هذا البعد يركز على توزيع المعرفة بين الأفراد ووصولها إليهم بصورة آمنة ، وتأهيل أفراد المجتمع لصناعة المعرفة ، وتأسيس المجتمع على أساس ريادة الأعمال فى مجال صناع المعرفة ، ومشاركة الأخرين الخبرات الثخصية (xxix).

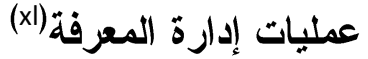

تتكون عمليات المعرفة من مجموعة من العناصر متمثلة فى عنصر توليد المعرفة ، وعنصر ونشر المعرفة ، و عنصر المشاركة بالمعرفة ، وعنصر أستخدام المعرفة ،

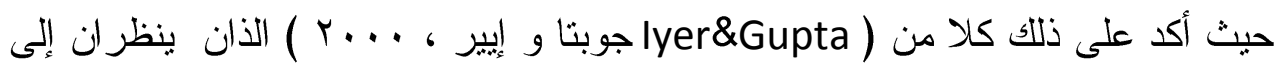
إدارة المعرفة بأنها عبارة عن أسر المعرفة واستقطابها ونقلها و تخزينها و التحكم بها ونشرها و حفظها مؤرشفة داخل المنظمة ، وبالإستخدام الفاعل لإدارة المعرفة سوف يسهل عمليات المنظمة الداخلية للعمل بسهولة واتخاذ الاجراءات اللازمة للرد على منافسى المنظمة وتمكين العاملين بالمنظمة بالمعرفة اللازمة على الفور ، وبما يدعم قدرة المنظمة التنافسية وتحقيق التميز المؤسسى ، فإدارة نظم المعرفة تعثبر مفهوم و منهج يستخدم تقنية المعلومات كأداة ووسيلة لتجميع وتخزين الخبرات و المعارف لتسهيل وتسريع المشاركة بها ونشر ها بأكبر قدر ممكن • 
الثكل رقم (1) يوضح كيفية إدارة نظم المعرفة

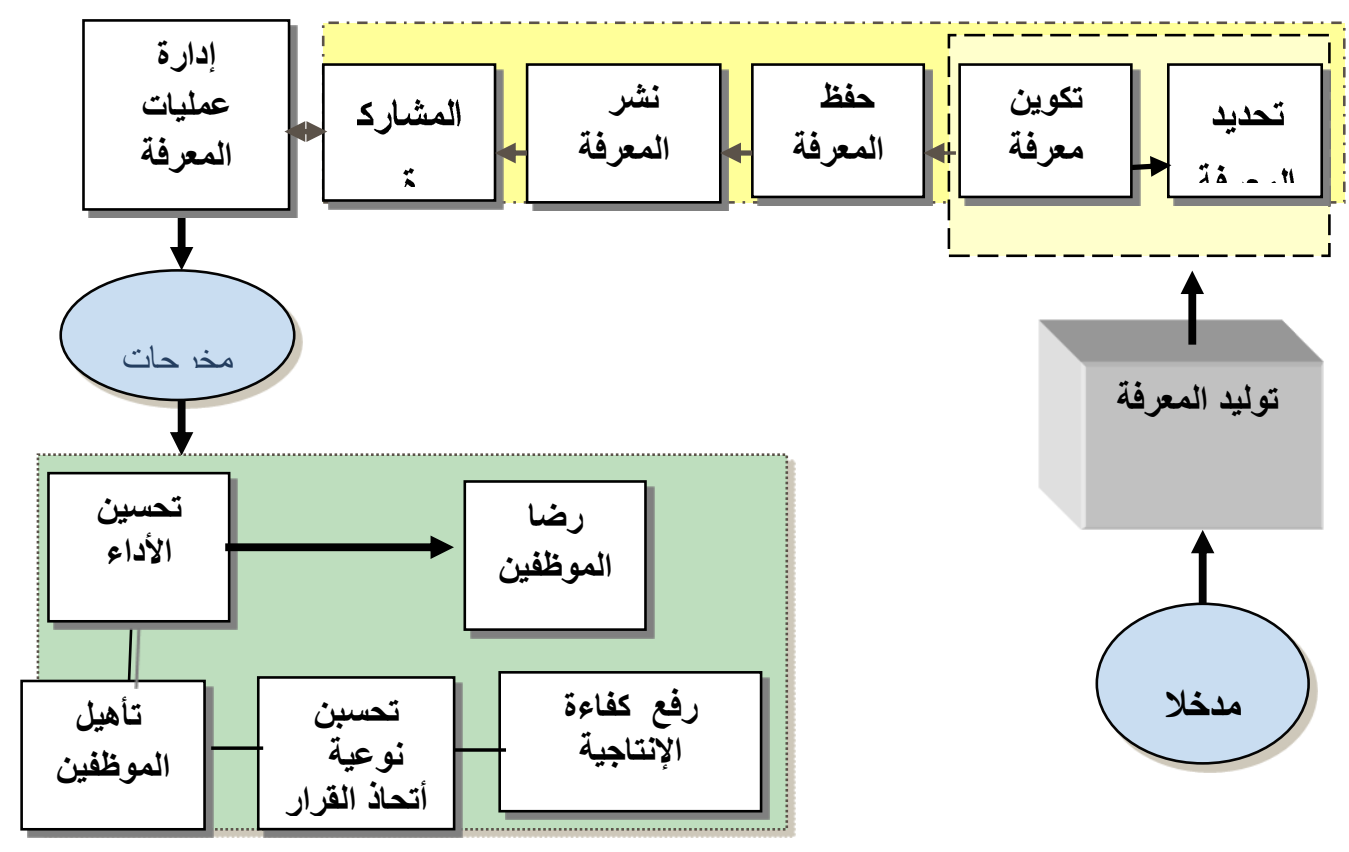

\section{معوقات إدارة المعرفة}

تثمثل معوقات تتفيذ إدارة المعرفة فى :

سيطرة الثقافة التي تحد من التشارك في المعرفة.

• عدم دعم القبادات فى الصفوف الأولى لإدارة المعرفة.

• عدم الإدر الك الكافي لمضمون إدارة المعرفة ومحتو اها.

• عدم الإدر الك الكافى لفو ائد إدارة المعرفة و أدو ارها بالمنظمة.

- الإفتقار إلى التكامل بين أنشطة المنظمة المرتبطة بإدارة المعرفة وبين تعزيز التعلم المنظمي.

• محدودية التدريب المرتبط بإدارة المعرفة.

• عدم إجادة كيفية استخدام وتنفيذ نظام إدارة المعرفة.

• عدم فهم إدارة المعرفة بشكل صحيح بسبب الإتصال غير الفعال وغير الكفؤ (xli). مै 


\section{منطلبات تطبيق إدارة المعرفة بمنظمات التعليم التطبيقى}

إن الهدف والغاية من إدارة المعرفة المتاحة للمؤسسات الأكاديمية بصفة عامة ومنظمات التعليم التطبيقى والتّريب على وجه الخصوص هو تطبيق المعرفة المتاحة فى الإطار التنظيمى ومحيطه البيئى ، و التي تعد من أبرز عملياتها و يعنى تطبيق المعرفة جعلها أكثر ملائمة للمستفيدين في تتفيذ الأنشطة المنوط القيام بها و أكثر ارتباطاً بالمهام التى تقوم بها ، استتادا إلى أنه من المفترض أن تقوم الهيئة بالتطبيق الفعال للمعرفة للإستفادة منها بعد إيداعها وتخزينها وتطوير سبل إسترجاعها ونقلها إلى العاملين (xlii) . فإدر الك منطلبات تطبيق إدارة المعرفة وضبط إدارة تلك المنطلبات يؤدي إلى خلق

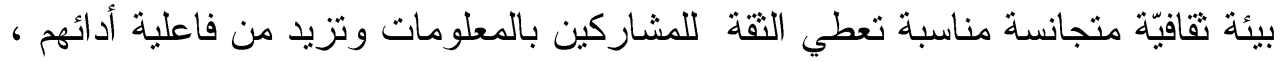
كما تهدف هذه المتطلبات إلى إتاحة فرص الإستمر ارية وتحقيق التنافسية ، حيث الإتاحة الكاملة لنشر ثقافة إدارة المعرفة ، ومعرفة وحماية المصادر الحالية لإدارة المعرفة بالمنظمة ، وخلق المناخ المؤسسى الذى يمكن وظيفة إدارة المعرفة بالمنظمة من البقاء و النمو بفاعلية ، ويجب الوضوح و المر اقبة بكل مرحلة من مر احل تطبيق إدارة المعرفة ، و هذه المتطلبات معتمدة اعتمادا كلياً على بعضها البعض ، وهى تلعب دور أساسيا لا غنى عنه في نجاح نطبيق إدارة المعرفة(xliii). وتشمل هذه المنطلبات الأتى :

اــ الثقافة التظيمية : تتضمن القيم والمعتقدات و المشاعر فى داخل المنظمة والتى تسود بين العاملين مثل طريقة تعامل الأفر اد مع بعضهم ، وتوقعات كل فرد من الأخر و من المنظمة

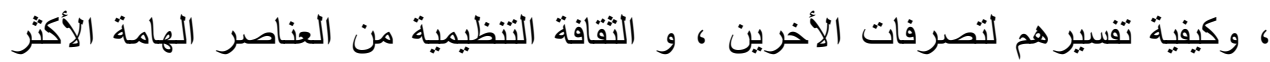
وجوباً لتطبيق إدارة المعرفة ، ، كما أن هناك عوامل تساعد على إدخال مفهوم إدارة

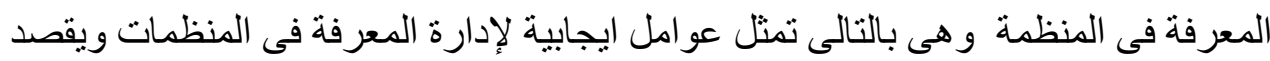
بها التى تشجع وتحث على العمل بروح الفريق وتبادل الأفكار ومساعدة الآخرين ، و القدوة و المثل الأعلى للقيادة الفعالة التى تساعد وتحفز على تبنى مفهوم إدارة المعرفة(xliv) . 
r- القيادة التظيمية : حيث أنه لا يوجد أسلوب و احد فى القيادة يصلح لكل زمان ومكان ، كما

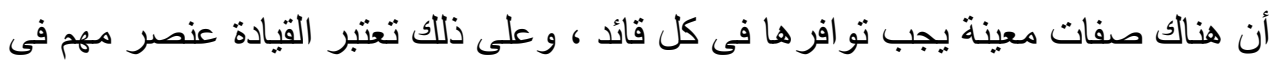
تبنى و تطبيق إدارة المعرفة(xlv) ، ويجب على المؤسسات الأكاديمية و منظمات التعليم التطبيقى الر اغبة فى تبنى إدارة المعرفة استحداث مسمى لوظيفة تعنى بإدارة المعرفة من

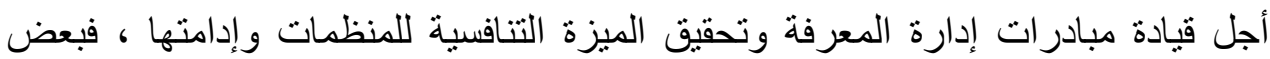
المؤسسات الامريكية والأوربية بطلقون على هذه الوظيفة مسمى ضابط المعرفة أو قائد

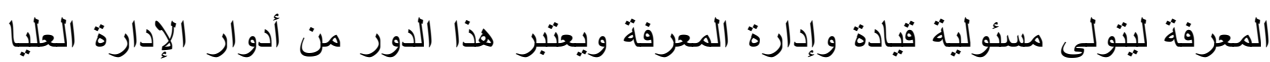
ويوازى دور مدير إدارة الموارد البشرية أو إدارة المعلومات(Xlvi) .

rــ الموارد البشرية : ويتمثل فى الكادر البشرى الذى يقوم بكافة أعمال المؤسسة الأكاديمية ويعتبر أحد أهم الموارد التى تعتمد عليه المنظمة فى البقاء و الاستمرارية ، إذ يعتبر كل

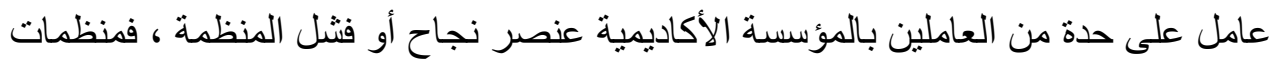
التعليم التطبيقى التى تسعى لتحقيق التميز و النجاح أنما هى التى تخلق وتبنى كوادر بشرية متميزة وماهرة ومتخصصة من خلال التدريب والتأهيل والتطوير المستمر ، فإن تنمية الموارد البشرية من خلال زيادة المعرفة والمهار ات والقدرات لدى العاملين فى المجالات المختلفة لرفع مستوى كفاءة الأداء يسهم بشكل كبير فى تطبيق عمليات وأنظمة إدارة

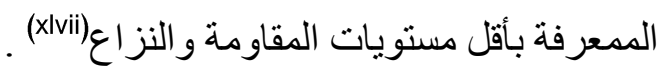
ـ ـ تكنولوجيا المعلومات : بمعنى تطبيق تكنولوجيا المعلومات بغية تحسين إنشاء المعرفة و تنظيمها وتطبيقها ، وتعد الأدوات التكنولوجية من الأسس الهامة فى تطبيق وممارسة

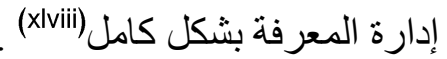




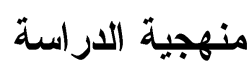

من أجل تحقيق أهداف الدراسة تم استخدام المنهج الوصفى التحليلى و الذى بعـرف

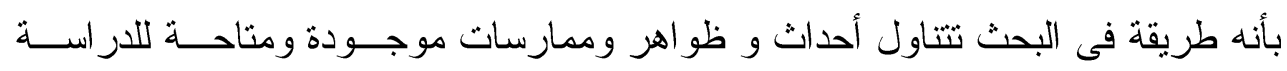

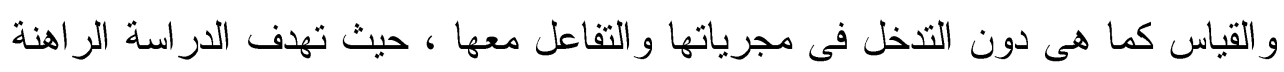

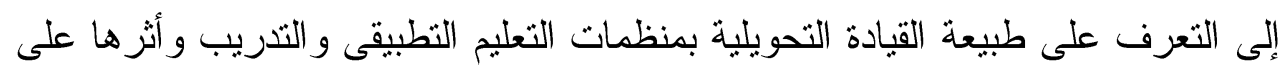
فعالية متطلبات تحقيق إدارة المعرفة .

وقد اعتمدت الدر اسة على كل من البيانات الأولية وذلك من خلال الجانب الميدانى

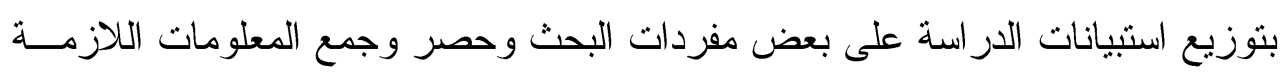

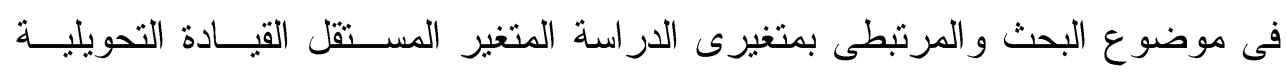

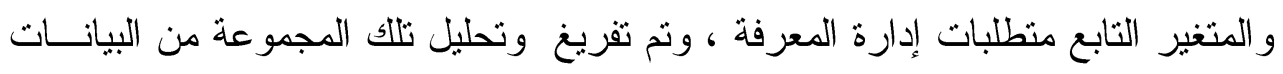

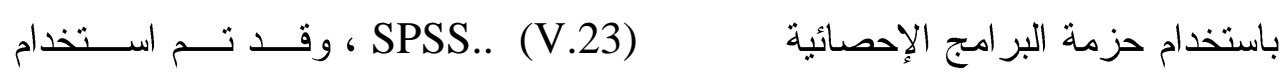

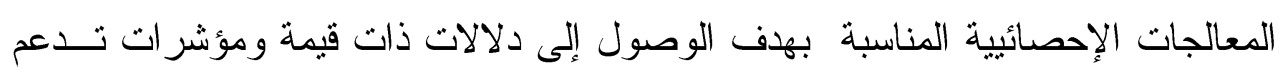

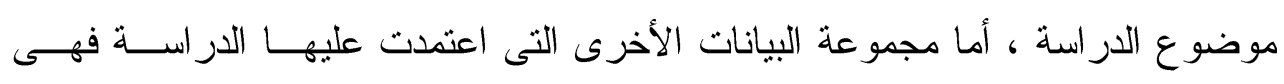

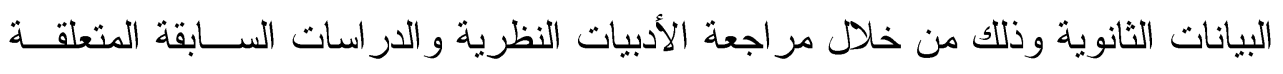

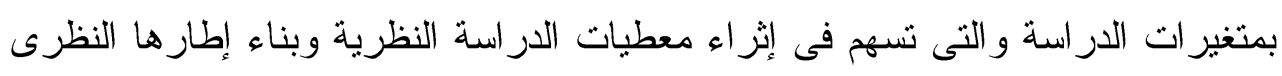

\section{مجتمع وعينة الدراسة}

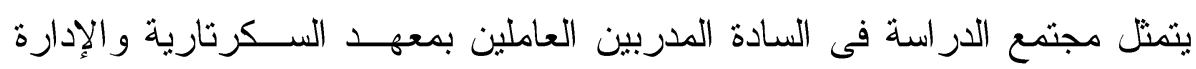

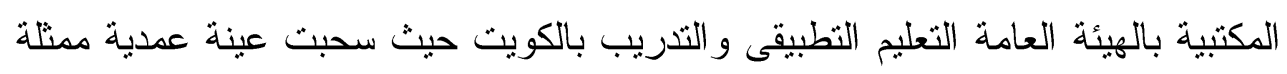

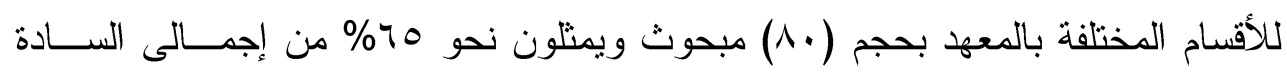

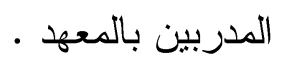

أدوات الدراسة.

يتوقف نجاح البحث فى تحقيق أهدافه على الاختبار الرشيد لأنسب الأدوات الملائمة

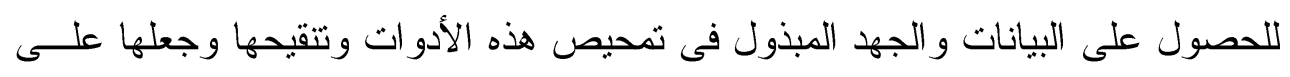


أعلى مستوى من الكفاءة ، فقد اعنمدت الباحثة فى هذه الدراسة على استمارة فياس تتقق

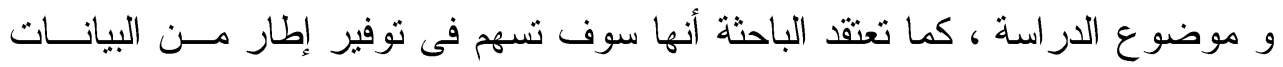

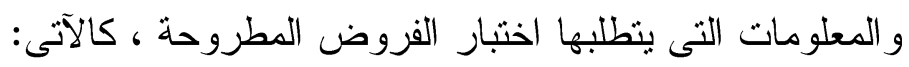

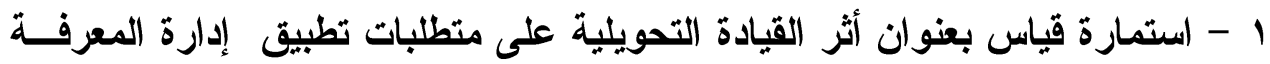
بمنظمات التعليم التطبيقى : دراسة من وجهة نظر السادة المدربين بمعهد الســكرتارية والإدارة المكتبية بالهيئة العامة للتعليم التطبيقى و التدريب بالكويت (إعداد الباحثة). بناء ادوات الادراسة : حاولت الباحثة من خلال كل من استمارة قياس أثر القيادة التحويلية على متطلبـات

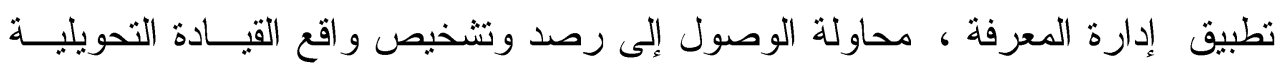

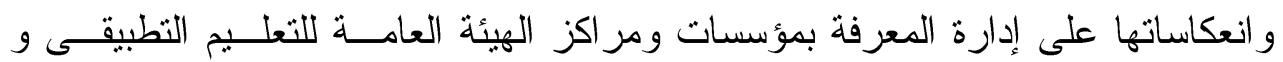

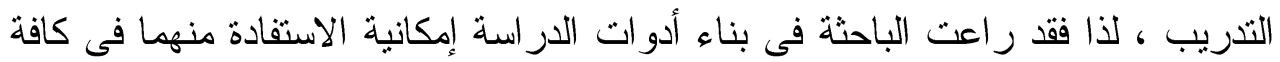

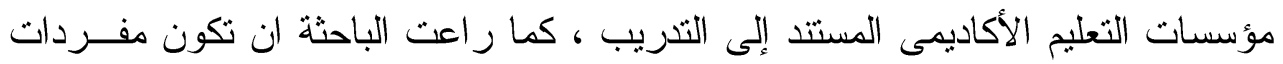

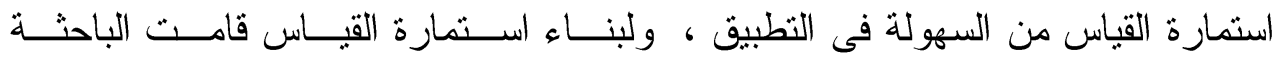

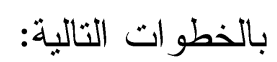
- حددت الباحثة أبعاد كل من القيادة التحويلية و منطلبات تطبيــق إدارة المعرفــة محــور

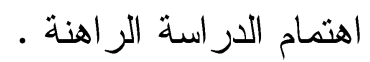

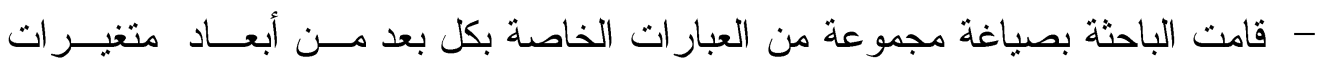
الار اسة الرئيسية و التى سوف تمثل مفردات القياس فى صورته النهائية فى ضو هـ الآتى:

المؤشر ات النى أسفر عنها الإطار النظرى للار اسة و الدر اسات السابقة.

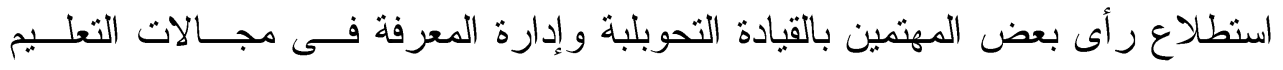

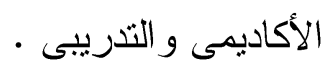

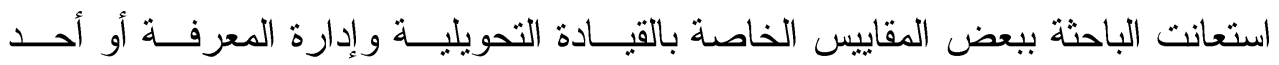
أبعادهما فى الدر اسة الر اهنة، وقد استتبطت الباحثة بعض الأفكار من هذه المقاييس.

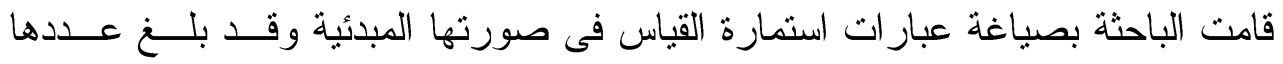

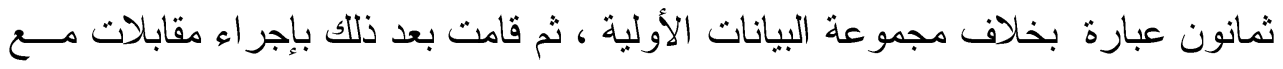

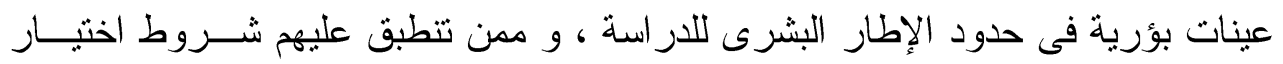


المبحوثين بعينة الدر اسة الر اهنة كمعيار لاختيار المفردة البؤرية ، كما راعت الباحثة أن

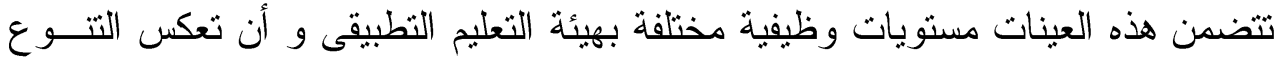
الوظيفى للعاملين بمعهد السكرتارية و الإدارة المكتبية قدر الإمكان ، حيث قامت الباحثة

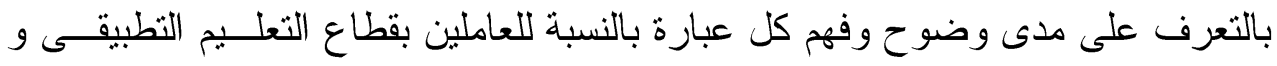

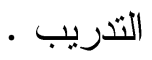
قامت الباحثة فى ضوء الخطوة السابقة بإعادة صياغة استمارة القياس تمهيداً لإخضاعها لعمليات الثقنين (اختبار الثبات و الصدق). أسفرت اختبار ات الثبات و الصدق لاستمارة القياس إلى توصل الباحثة إلى صياغتها فـى

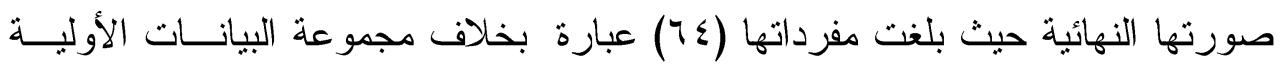

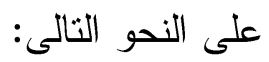

جدول رقم (1) يوضح عدد عبارات استمارة قياس أثر القيادة التحويلية على منطلبات

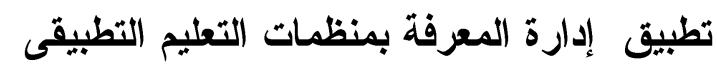

\begin{tabular}{|c|c|c|c|c|}
\hline \multicolumn{2}{|c|}{ أرقام العبارات } & \multirow{2}{*}{ العبارا } & \multirow{2}{*}{ المحور / البعد } & \\
\hline 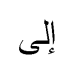 & من & & & \\
\hline$\wedge$ & 1 & $\wedge$ & 1 -بعد : التأثثر الكارزمى & \multirow{4}{*}{ 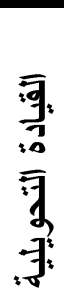 } \\
\hline 19 & 9 & $\Lambda$ & r- بعد : التحفيز الإلهامى & \\
\hline$r \varepsilon$ & iv & $\Lambda$ & ب- بعد : الإستثارة الفكرية & \\
\hline Mr & ro & $\Lambda$ & ع - بعد : الإعتبار ات الفردية & \\
\hline$\varepsilon$ & $r r$ & $\lambda$ & ه- بعد : الثقافة النتظيمية & 9 \\
\hline$\varepsilon \wedge$ & 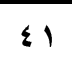 & $\lambda$ & 4- بعد : القيادة التنظيمية & 青. \\
\hline 07 & $\varepsilon 9$ & $\Lambda$ & V- بعد : الموارد البشرية & $\frac{\sqrt{2}}{10}$ \\
\hline $7 \varepsilon$ & ov & $\wedge$ & 1- بعد : تكنولوجيا المعلومات & 雪 \\
\hline
\end{tabular}

تصحيح استمارة قياس أثر القيادة التحويلية علــى متطلبــات تطبيـق إدارة المعرفــة بمنظمات التعليم التطبيقى. 


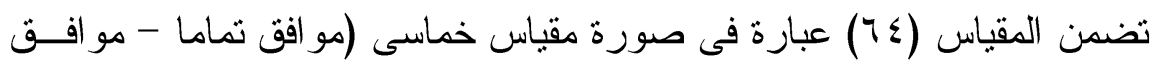

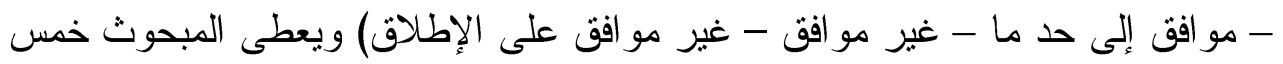

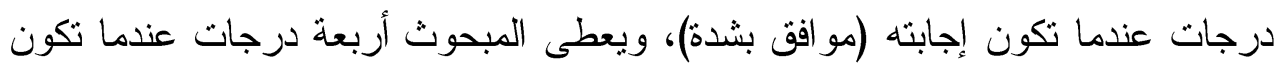

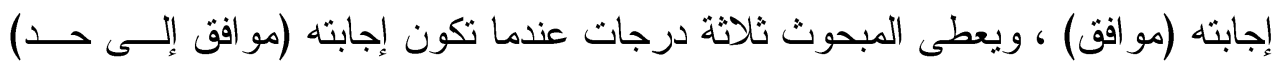

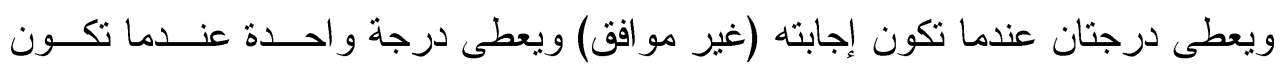
إجابته (غير موافق على الإطلاق).

ثبات وصدق استمارة قياس أثر القيادة التحويلية على منطلبات تطبيق إدارة المعرفة

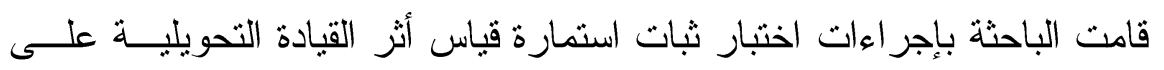

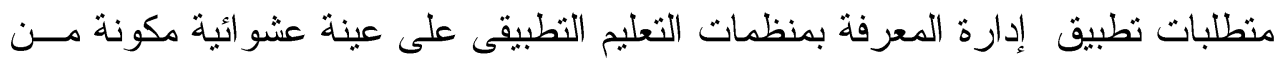

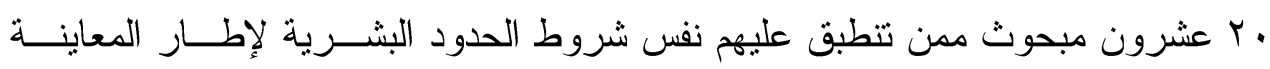
بالدر اسة كما قامت الباحثة بإجر اءات اختبار صدف استمارة قياس أثز القيادة التحويليـــة

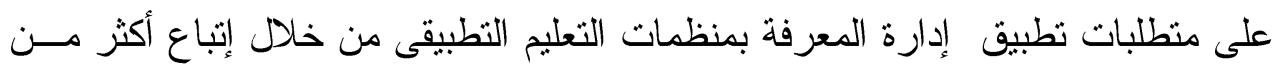

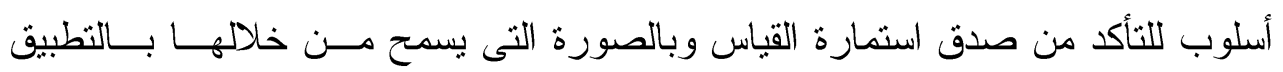
الميدانى.

ثبات استمارة قياس أثر القيادة التحويلية على متطلبات تطبيق إدارة المعرفة .

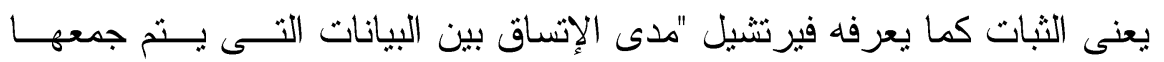

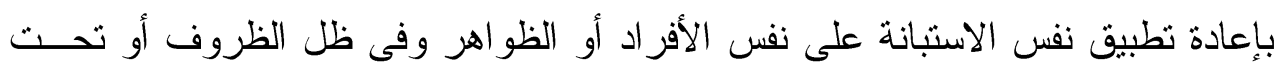

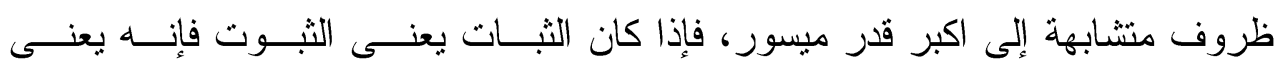

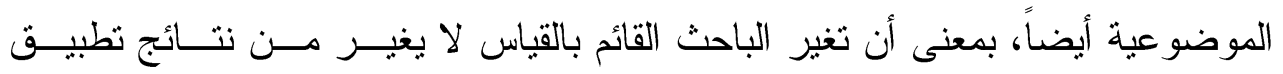

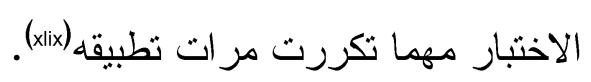
وقد اعتمدت الباحثة على أكثر من أسلوب للتحقى من ثبات المقياس: - ثبات التتصيف. - - إعادة التطبيق.

إعادة التطبيق:

قام الباحثة بنطبيق المقياس على عينة عشو ائية قو امها عشرون مبحــوث مدــن

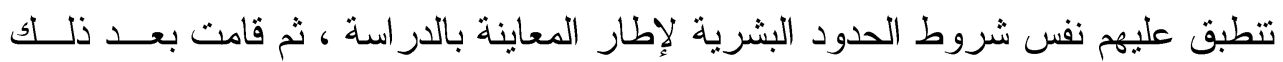

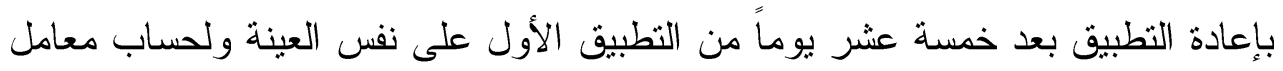

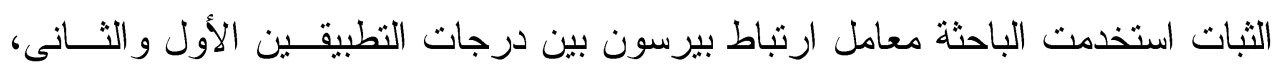




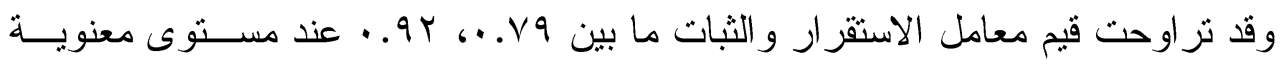

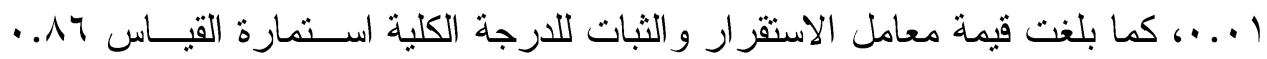

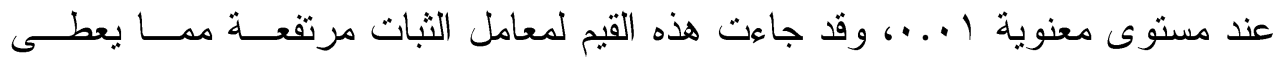

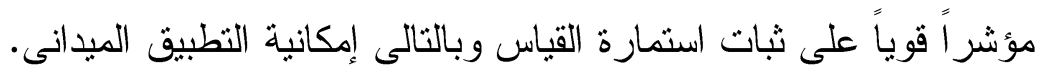

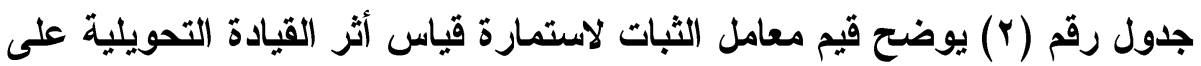
متطلبات تطبيق إدارة المعرفة بمنظمات التعليم التطبيقى بواسطة إعادة التطبيق.

\begin{tabular}{|c|c|c|}
\hline معامل الثبات & المحور / البعد & \\
\hline. .10 & 1- بعد : التأثير الكارزمى & \multirow{4}{*}{ 可司哥 } \\
\hline. .19 & بعد : التحفيز الإلهامى & \\
\hline$\because .9$ & r- بعد : الإستثارة الفكرية & \\
\hline. .10 & ع- بعد : الإعتبار ات الفردية & \\
\hline. .19 & 0- بعد : الثقافة التنظيمية & \multirow{4}{*}{ 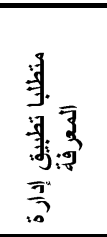 } \\
\hline$\overline{. .1 \Lambda}$ & بعد : القيادة التنظيمية & \\
\hline$\cdot .11$ & بعد : المو ارد البشرية & \\
\hline$\cdot .94$ & ᄉ- بـ بعد : تكنولوجيا المعلومات & \\
\hline. .14 & \multicolumn{2}{|c|}{ معامل ثبات الدارجة الكلية لأستمارة القياس } \\
\hline
\end{tabular}

ثبات التنصيف:

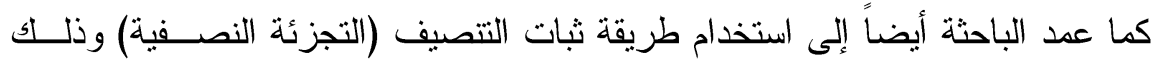

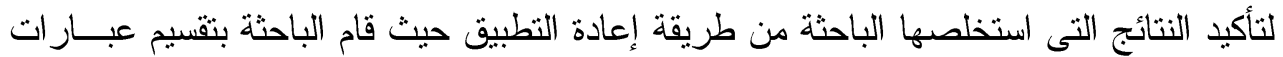

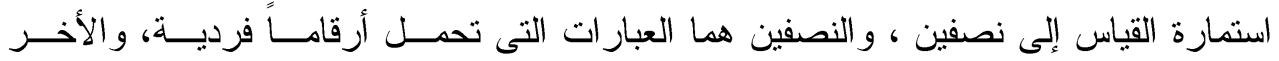

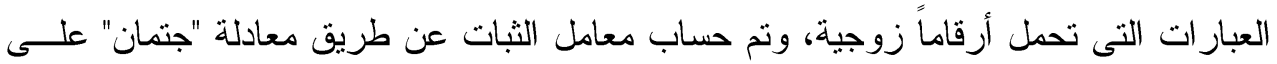

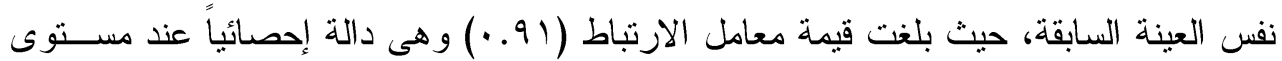
معنوية (1. . . م. ويعد ذلك معاملاً مرتفعاً.

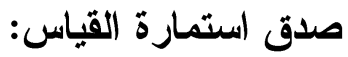
يعتبر الاستبيان المستخدم لقياس ظاهرة صـادقاً إذ كان هذا الاستبيان يقـيس الظــــاهرة

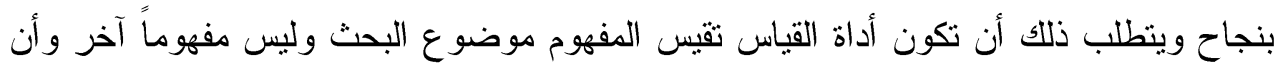

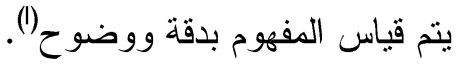
وقد اعتمدت الباحثة على أكثر من أسلوب للتحقق من صدق استمارة القياس:

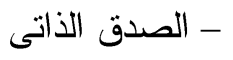

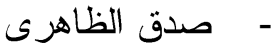




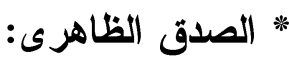

بعد قيام الباحثة بإعداد استمارة القياس فى صورتها المبائية حيث تضمنت •1 ثمانون

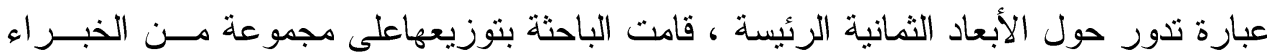

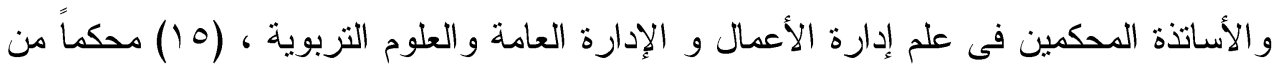

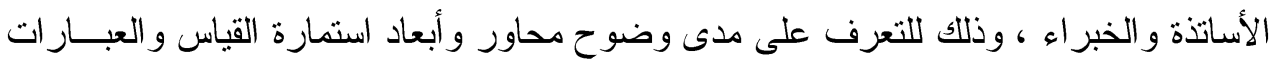

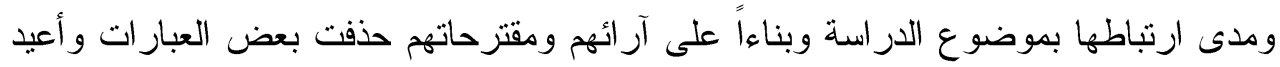

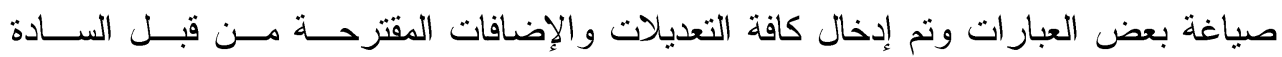

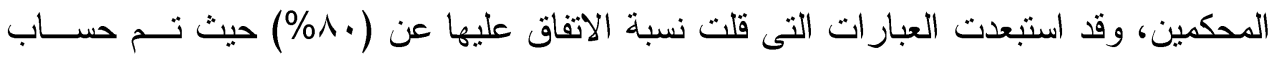
نسبة الاتفاق وفقاً للمعادلة التالية:

\begin{tabular}{|c|c|c|}
\hline$x$ & عداد مرات الاتفاق & نسية الاتفاق = \\
\hline $1 \cdots$ & عدد مرات الاتفاق + عدد مرات الاختلاف & 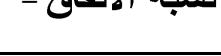 \\
\hline
\end{tabular}

$$
\text { : الصدق الذاتى: }
$$

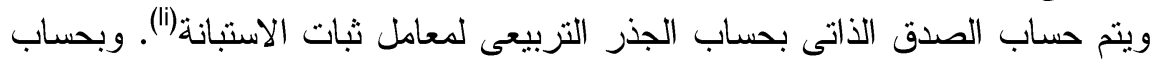
الجذر التربيعى لمعامل ثبات استمارة القياس ، وجد أن معامل الصدق الذاتى لمحاور اســـمارة

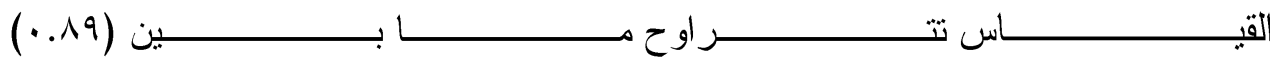

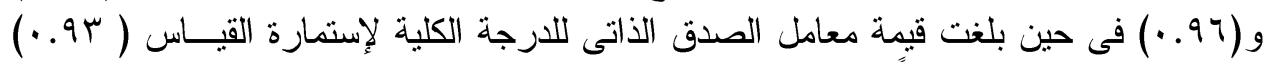

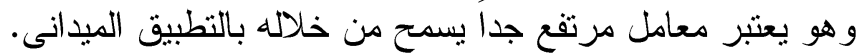

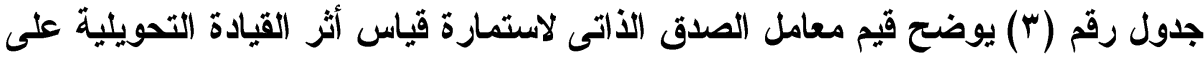

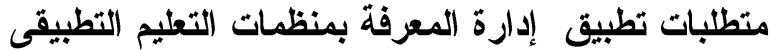

\begin{tabular}{|c|c|c|}
\hline الذاتدق & المحور / البعد & \\
\hline$\cdot .9 Y$ & 1- بعد : التأثيُ الكارزمى & \multirow{4}{*}{$\begin{array}{l}\text { 哥可 } \\
\text { 寻 }\end{array}$} \\
\hline$\cdot .9 \leqslant$ & r- بعد : التحفيز الإلهامى & \\
\hline$\because .90$ & r- بعد : الإستثارة الفكرية & \\
\hline$\cdot .9 \mathrm{Y}$ & ؟- بعد : الإعتبارات الفردية & \\
\hline$\cdot .19$ & 0- بعد : الثقافة التنظيمبة & \multirow{4}{*}{ 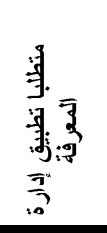 } \\
\hline $.9 \varepsilon$ & 7- بعد : القبادة التنظيمبة & \\
\hline$\because .9$ & V- بعد : المو ارد البشرية & \\
\hline$\cdot .97$ & 1- بعد : تكنولوجيا المعلومات & \\
\hline. .94 & \multicolumn{2}{|l|}{ معامل الصدق الأتى للارجة الكلية } \\
\hline
\end{tabular}




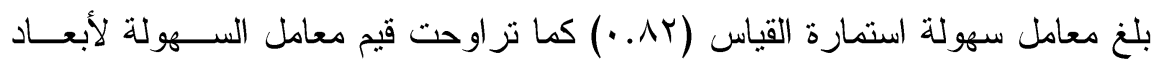

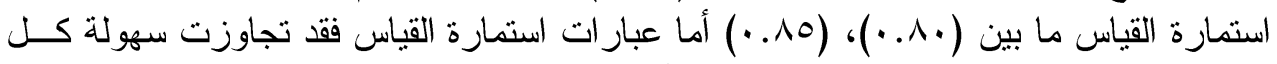

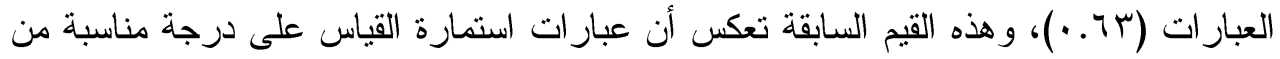

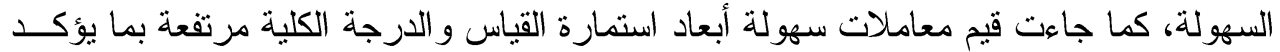

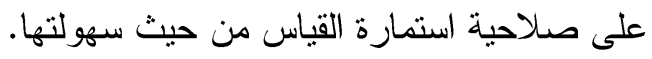

اختبار التوزيع الطبيعى ( اختبار كولمجروف - سمرنوف ( 1-Sample - K - S ) يسهم اختبار كولمجروف - سمرنوف (1) Sample - K - S) في معرفة ما إذا كانــت

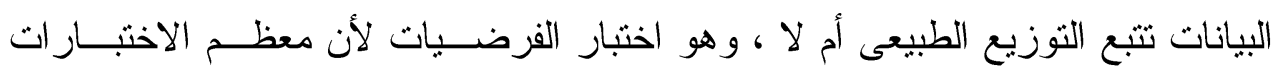

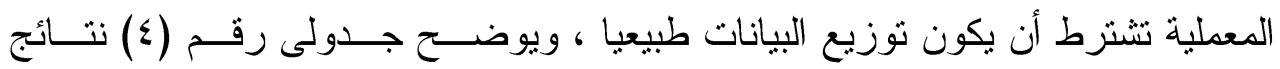

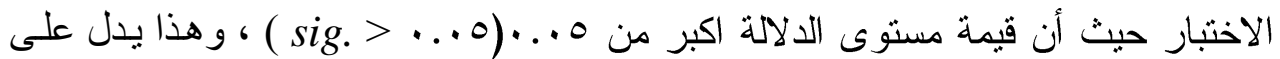
أن البيانات تتبع التوزيع الطبيعى ويجب استخدام الاختبار ات المعطلية .

جدول رقم ( ) اختبار التوزيع الطبيعى ( 1-Sample - K-S) لاستمارة قياس أثر

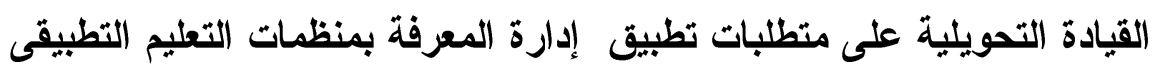

\begin{tabular}{|c|c|c|c|}
\hline مستوى & قيمة Z ق & محاور / أبعاد استمارة القياس & \\
\hline$\ldots .0 \mathrm{~V}$ & $1 . r r \varepsilon$ & 1-بعد : التأثثر الكارزمى & \multirow{4}{*}{ 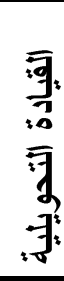 } \\
\hline..$r) \leqslant$ & 1.00 & r- بعد : التحفيز الإلهامى & \\
\hline. $.1 A Y$ & $1 . .19$ & r- بعد : الإستثارة الفكرية & \\
\hline. .179 & 1.111 & ع- بعد : الإعتبار ات الفردية & \\
\hline. TYA &. .990 & 0- بعد : الثقافة التنظيمية & \multirow{4}{*}{ 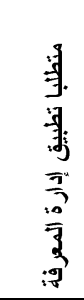 } \\
\hline . &. .101 & 4- بعد : القبادة التتظيمية & \\
\hline$\cdot . \varepsilon \cdot r$ &..$\wedge 9 \%$ & V- بعد : الموارد البشرية & \\
\hline.+ r. & $1 \ldots 9$ & ^- - بعد : تكنولوجيا المعلومات & \\
\hline$. . r+q$ & $. .9 \leqslant 9$ & \multicolumn{2}{|c|}{ معامل الآتساق الداخلى للارجة الكلية لأستمارة القياس } \\
\hline
\end{tabular}


تحليل بيانات الاراسة الميدانية ونتائجها جدول رقم (ه) توزيع أفر اد عينة البحث وفقا لبعض المتفيرات المرتبطة بخصائص مجتمع الدراسة

\begin{tabular}{|c|c|c|c|}
\hline \multicolumn{2}{|c|}{ A. $=\dot{ن}$} & \multirow{2}{*}{\multicolumn{2}{|c|}{ المتغير }} \\
\hline$\%$ & ك & & \\
\hline 70 & or & ذكر & \multirow{2}{*}{$\begin{array}{l}\bar{\sigma} \\
\omega\end{array}$} \\
\hline ro & ru & أنثى & \\
\hline rY.O & 11 & أقل من •r T & \multirow{7}{*}{$\overline{3}$} \\
\hline Tr.vo & 11 & من ·ro-r سنة & \\
\hline T1.ro & ro & من 0r - .ع سنة & \\
\hline IV.0 & $1 \varepsilon$ & من ·ـ - 0؛ سنة & \\
\hline 10 & $T$ & 0ـ سنة فأكثر & \\
\hline \multicolumn{2}{|c|}{$r 9.9$} & الوسط الحسابي & \\
\hline \multicolumn{2}{|c|}{$7 . \wedge$} & الإنحر اف المعبارى & \\
\hline rT.VO & rV & بكالوريوس & \multirow{4}{*}{ 䨌 } \\
\hline$\varepsilon$. & rr & دبلوم در اسات عليا & \\
\hline Yr.O & 11 & ماجيستير & \\
\hline r.vo & r & دكتور اه & \\
\hline
\end{tabular}

يتضح من بيانات الجدول السابق أن \%\% من إجمالى المبحوثين بعينة الدراسة

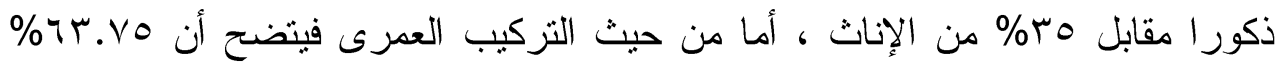

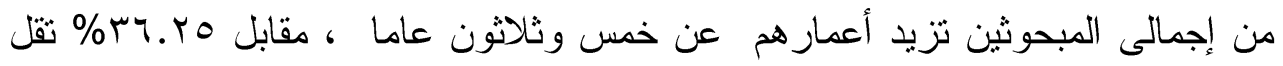

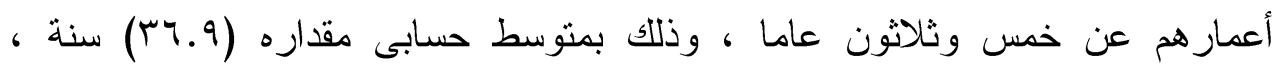

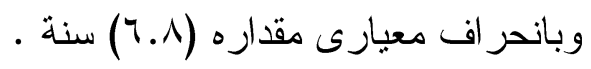

كما أوضحت بيانات الجدول السابق أيضا أن •ـ٪ من إجمالى المدربين بعينة

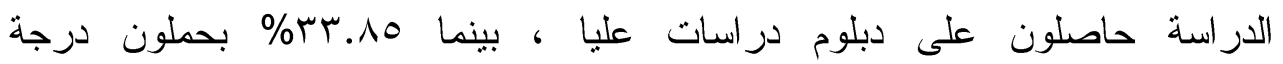

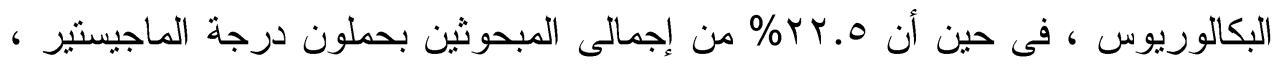

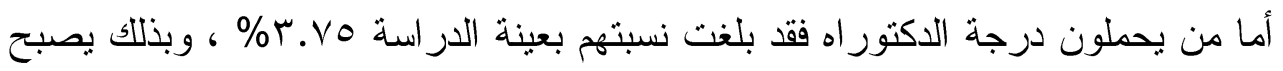

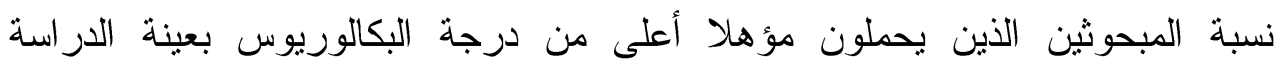

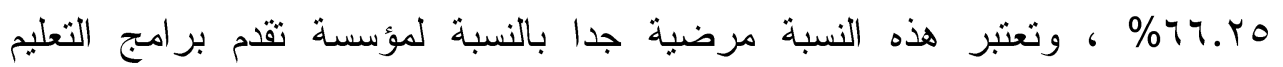


و التنريب التطبيقى ، وتسعى لبناء كو ادر وطنية تسهر بايجابية فى دفع عجلة التنمية · بالمجنمع الكويتى

\section{النتائج الخاصة بالتحقق من فروض الدراسة}

للتحقق من صحة الفرض الرئيسى و الذى مؤداه " أنه توجد علاقة ايجابية بين

القيادة التحويلية و متطلبات تطبيق إدارة المعرفة و المتمثلة فى ( الثقافة التنظيمية -

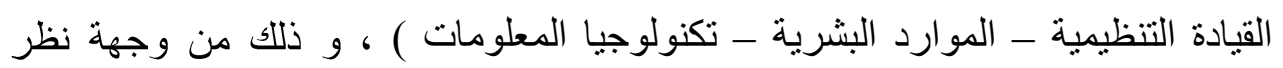

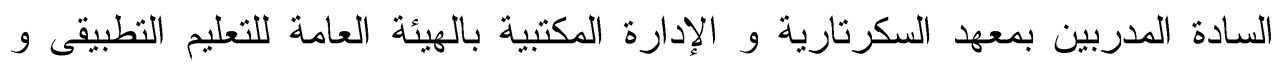

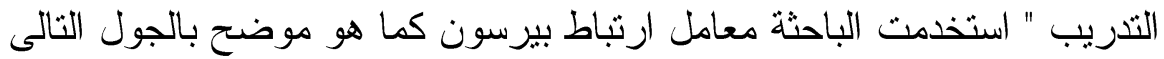
جدول رقم (7) يوضح العلاقات الارتباطية بين متغيرى الارسة القيادة التحويلية و إدارة المعرفة باستخدام معامل ارتباط بيرسون

\begin{tabular}{|c|c|c|c|c|c|c|c|c|c|c|c|}
\hline \multicolumn{5}{|c|}{ إدارة المعرفة } & \multicolumn{5}{|c|}{ القيادة التحويلية } & \multirow{2}{*}{\multicolumn{2}{|c|}{$\Lambda \cdot=\dot{ن}$}} \\
\hline لالبعاد إدادة الكلة & تكنولبوجيا & "البشرية البرد & بعتد القيادة & بعند الثقافة & 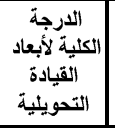 & الإلفتباردات & الإلفكتثارة & بعد الإلتحفيز & |أكعارزمىي & & \\
\hline $.985^{* *}$ & $.426^{* *}$ & $\begin{array}{l}.436^{* *} \\
.000\end{array}$ & $\begin{array}{l}.428^{* *} \\
.000\end{array}$ & $.629^{* *}$ & 1 & $\begin{array}{l}.408^{* *} \\
.000\end{array}$ & $\begin{array}{l}.455^{* *} \\
.000\end{array}$ & $\begin{array}{l}.433^{* *} \\
.000\end{array}$ & $\begin{array}{l}.639^{* *} \\
.000\end{array}$ & \begin{tabular}{|l} 
Pearson \\
sig. (2- \\
tailed)
\end{tabular} & الألتابلدية \\
\hline 1 & $.474^{* *}$ & $.439^{* *}$ & $.444^{* *}$ & $.600^{* *}$ & $.985^{* *}$ & $.429^{* *}$ & $\begin{array}{l}.443^{* *} \\
.000\end{array}$ & $\begin{array}{l}.436^{* *} \\
.000\end{array}$ & $\begin{array}{l}.604^{* *} \\
.000\end{array}$ & \begin{tabular}{|l} 
Pearson \\
sig. (2-. \\
tailed)
\end{tabular} & الألإبعادة \\
\hline
\end{tabular}

توضح بيانات يوضح الجدول (0) علاقات الارثباط التـي افترضـتنها الفرضــية الرئيسة للار اسة، إذ يؤكد الجدول السابق على وجود علاقة ارتباط إيجابية ومعنوية بـين

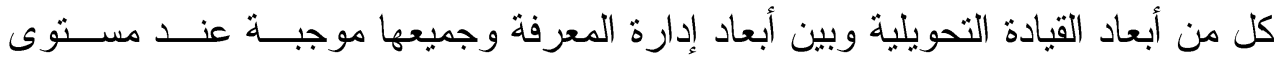

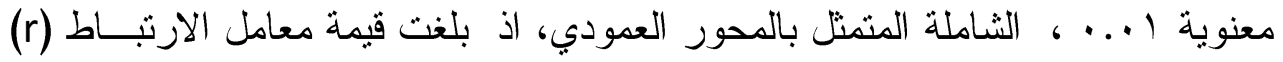
بين الدرجة الكلية لأبعاد القبادة التحويليــة ، و الدرجــة الكليــة لأبعـــاد إدارة المعرفــة

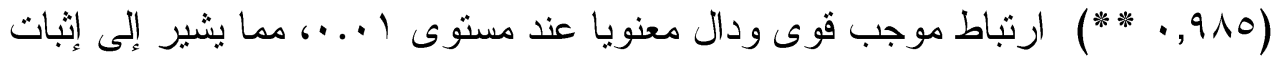
الفرضية الرئيسة الأولى الني مفادها (هنالك علاقة ارتباط معنوية ذات دلالة إحصائية بين

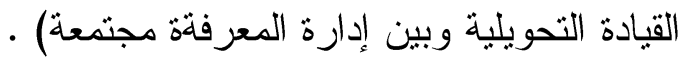


للتحقق من صحة فروض الدراسة الفرعية استخدمت الباحثة معامل الإنحدار البسيط بين

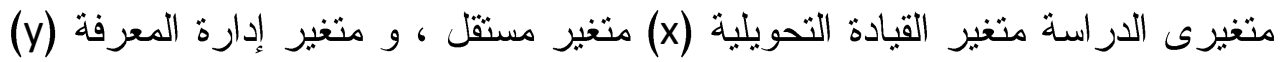
متغير تابع ، وذللك كما هو موضح بالجول التالى

جدول رقم (V) يوضح نتائج معامل الاحدار البسيط بين متغيرى الدراسة القيادة التحويلية(x) و وإدارة (المعرفة (y)

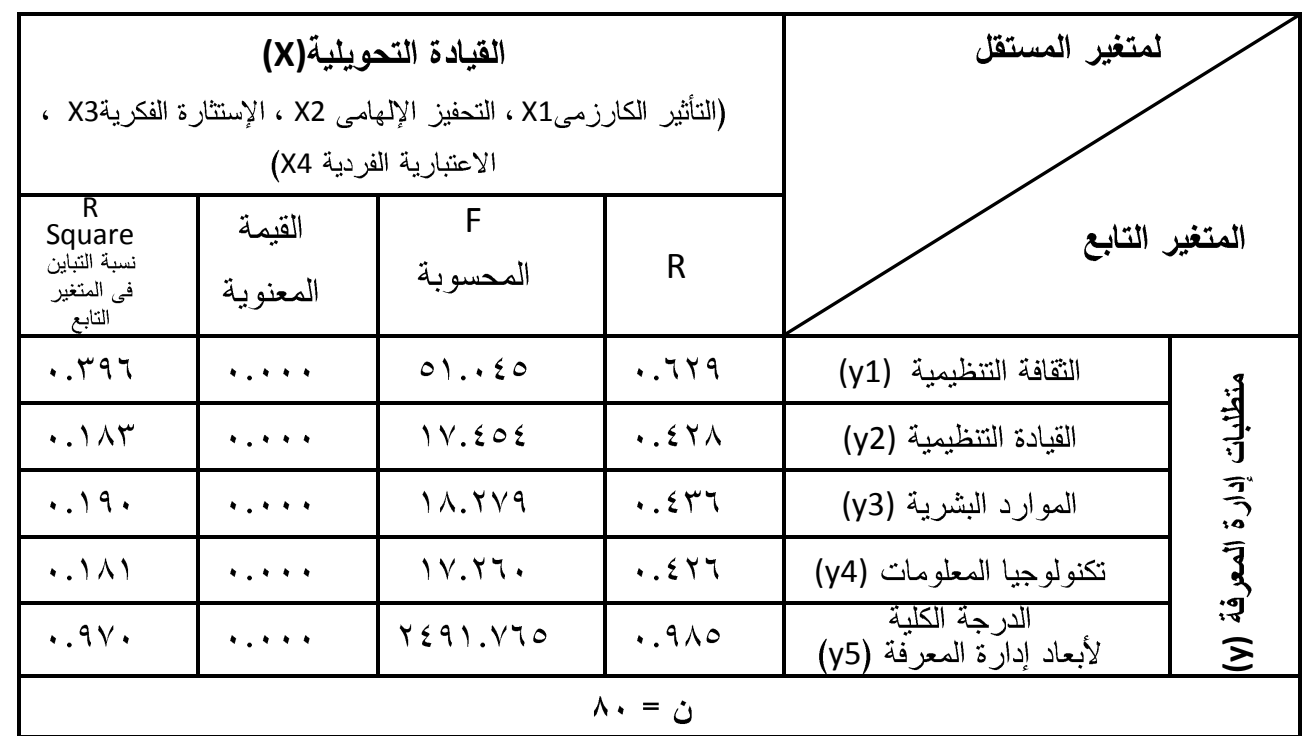

يتضمن الجدول السابق تحليل علاقات التأثير بين متغيرى الدراسة القيادة التحويلية و إدارة المعرفة الشاملة ، وذللك باستخدام إسلوب الانحدار البسيط ، نم اختبار

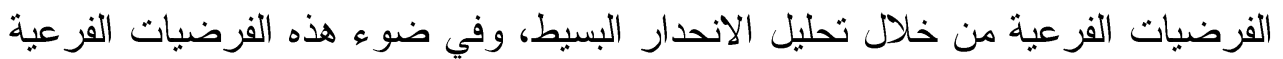
تم صياغة علاقة دالة بين المتغير التفسيري الرئيسى (القيادة التحويلية) الذي جرى ولئي تزميزه بالرمز (X) ، و المتغير التابع إدارة المعرفة والذي رُمز بالرمز (Y)، وفي ضوء الجدول رقم (V) لتحليل الانحدار البسيط ، الذي ظهر من مخرجات النظام الإحصائي . (SPSS , v23)

تظهر معنوية تحليل الإنحدار البسيطوفق اختبار F حيث يلغت قيمتا المحسوبة بين الدرجة الكلية لأبعاد القبادة التحويلية (x) و الدرجة الكلية لأبعاد إدارة المعرفة (y)

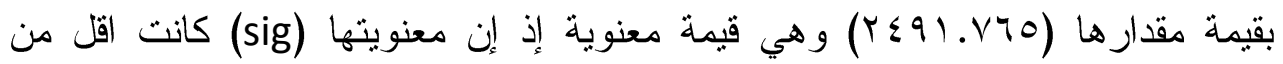

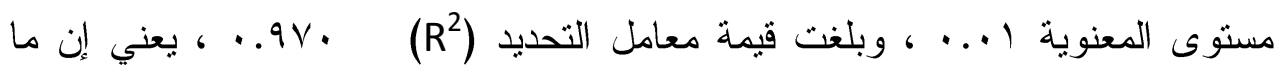




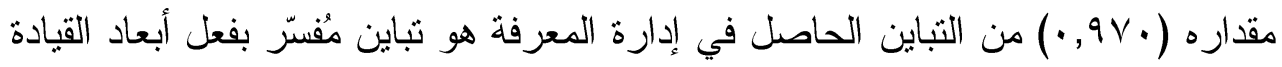

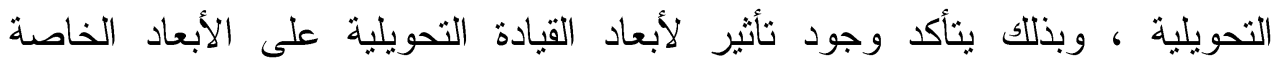

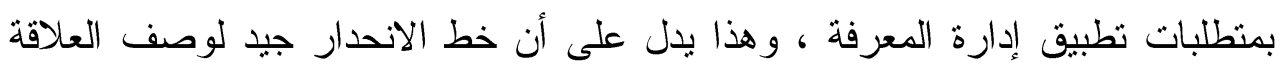
بين المتغيرين . بين أما بالنسبة لإختبار الفرضيات الفرعية فكانت على النخو التالى ؛1- نصت الفرضية الفرعية الأولى على وجود علاقة ايجابية ذات أثر بين القيادة التحويلية و بعد الثقافة التظظيمة كأحد منطلبات نطبيق إدارة المعرفة ، تظهر معنوية تحليل الإنحدار البسيط وفق اختبار F حيث يلغت قيمتها المحسوبة (0؛ ...10) و ذلك بين الدرجة الكلية لأبعاد القيادة التحويلية (x) ودرجة بعد الثقافة التنظيمية كأحد متطلبات تطبيق إدارة المعرفة (y) ، وهي قيمة معنوية إذ أن معنويتها (sig) كانت اقل من مستوى المعنوية

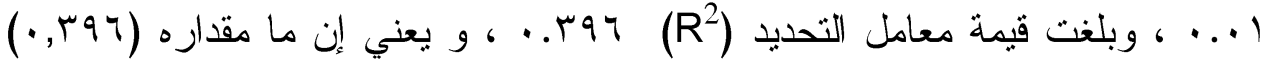
من التباين الحاصل في بعد الثقافة التنظيمية لإدارة المعرفة هو تباين مُفسّر بفعل أبعاد

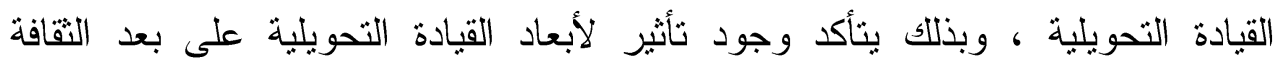
التنظيمية الخاص بمنطلبات نطبيق إدارة المعرفة ، وهذا يدل على أن خط الاتحدار جيد لوصف العلاقة بين المتغيرين .

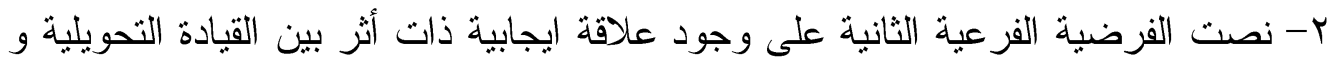
بعد القيادة التنظيمية كأحد منطلبات تطبيق إدارة المعرفة ، تظهر معنوية تحليل الإنحدار

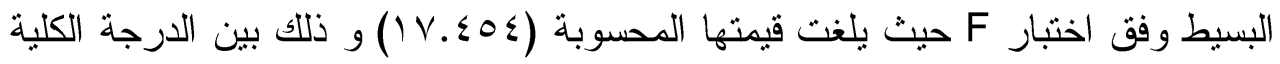
لأبعاد القيادة التحويلية (x) ودرجة بعد القيادة التنظيمية كأحد منطلبات تطبيق إدارة

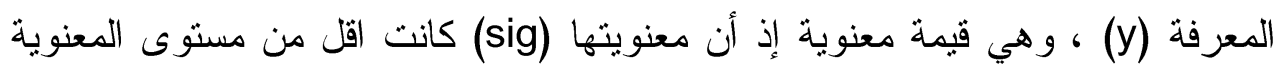

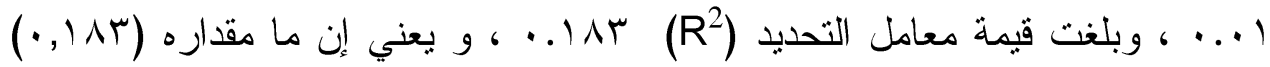
من التباين الحاصل في بعد القيادة التتظيمية لإدارة المعرفة هو تباين مُفسرّ بفعل أبعاد

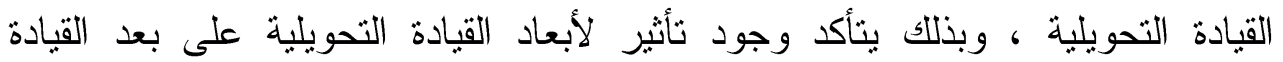
التنظيمية الخاص بمنطلبات تطبيق إدارة المعرفة ، وهذا بدل على أن خط الانحدار جيد لوصف العلاقة بين المتغيرين . 
r- نصت الفرضية الفرعية الثالثة على وجود علاقة ايجابية ذات أثز بين القيادة التحويلية و بعد الموارد البشرية كأحد منطلبات نطبيق إدارة المعرفة ، تظهر معنوية تحليل الإنحدار البسيط وفق اختبار F حيث يلغت قيمنها المحسوبة (X.YV9) و ذللك بين الدرجة الكلية لأبعاد القيادة التحويلية (x) ودرجة بعد الموارد البشرية كأحد منطلبات تطبيق إدارة

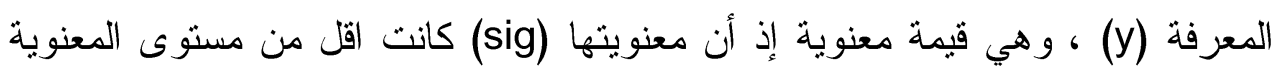

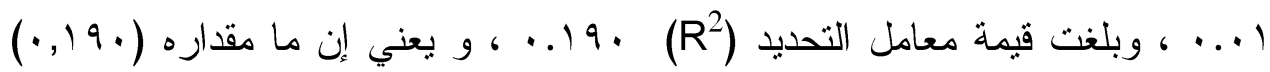

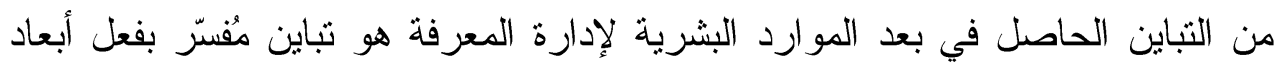

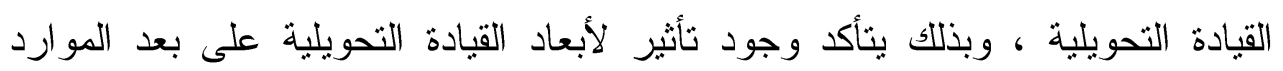

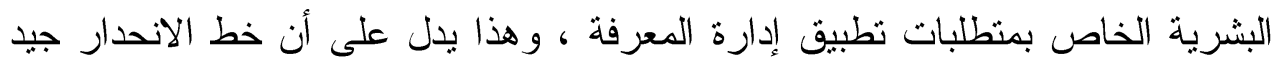
لوصف العلاقة بين المتغيرين . ع- نصت الفرضية الفرعية الر ابعة على وجود علاقة ايجابية ذات أثر بين القيادة التحويلية و بعد تكنولوجيا المعلومات كأحد منطلبات نطبيق إدارة المعرفة ، نظهر معنوية تحليل

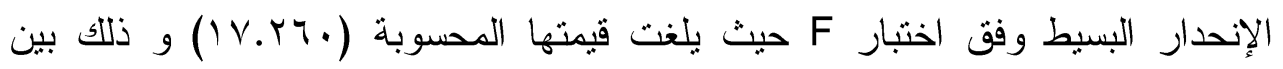
الدرجة الكلية لأبعاد القيادة التحويلية (x) ودرجة بعد تكنولوجيا المعلومات كأحد منطلبات

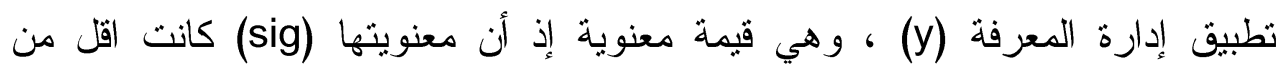

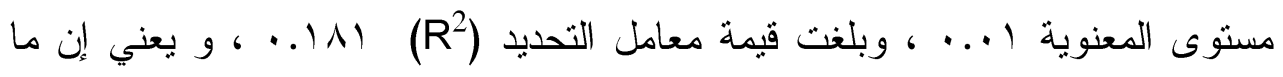

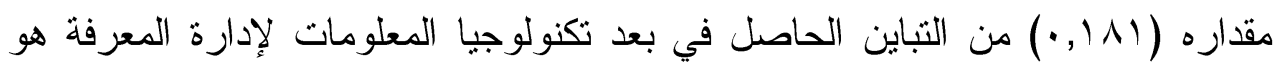
تباين مُفسر بفعل أبعاد القيادة التحويلية ، وبذللك يتأكد وجود نأثير لأبعاد القيادة التحويلية

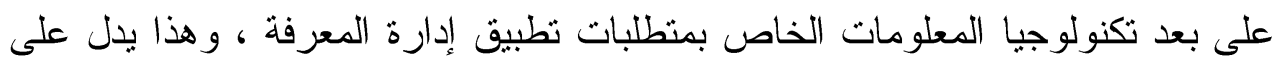
أن خط الانحدار جيد لوصف العلاقة بين المتغيرين . 
ا - الععل على رفع مستوى مشاركة المدربين فى معهد السكرتارية والإدارة المكتبية بالهيئة العامة للتعليم التطبيقى و التدريب من خلال إثر اكهم في العملية الإدارية و إظهار الاهتمام بأفكار هم و أر ائهم و الأي سينعكس على تعزيز متغيرى الدر اسة الر اهنة . ل

r - ضرورة حث إدارة معهد السكرتارية والإدارة المكتبية بالهيئة العامة للتعليم التطبيقى و التدريب السادة المدربين لتقديم اقتراحاتهم و أرائهم بشأن المشكلات التي تعترضهم، فضلاً عن ثقديم أفكار هم بخصوص ثطوير العملية التعليمية و التذريبية بالمعهد ، مما يجعلهم أكثر استعداداً لتوليد الأفكار المبدعة في الوقت الملائم .

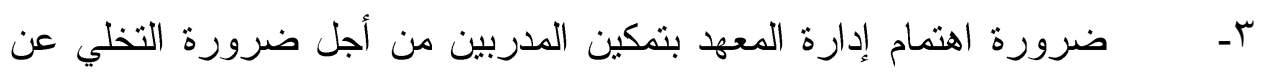
الأساليب و النظد التقليسية للإدارة ليتمكن المعهد من الوصول إلى التحسين المستمر في الخدمات و البر امج المقدمة وما لذلك من ثأثثر على تحقيق التنافسية . ع - ضرورة أن تعي القيادات الإدارية في المعهد بأهمية امتلاكها لمستوى جيد من سمات القيادة التحويلية و الذي سوف ينعكس ايجابيا على واقع إدارة المعرفة التى تعد مطلبا اساسيا للتميز المؤسسى. 


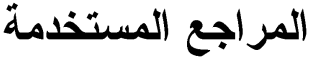

(') تركى بن نايف الدعجانى : بناء نموذج للقيادة الإدارية لتتمية الإبداع الإارى فى ، حرس الحدود باستخدام أسلوب دلفى، رسالة دكتوراه ، جامعة نايف الإباء العربية

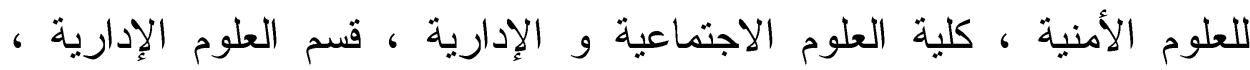
.r. $1 \varepsilon$

(") زواتيني عبد العزيز : الممارسة القيادية وعلاقتها بتحفيز العاملين دراسة حالة

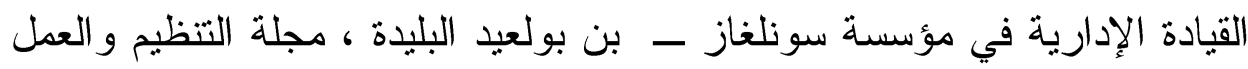

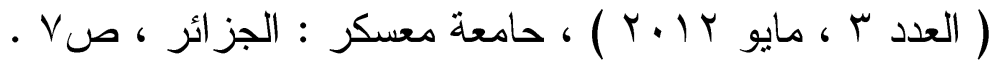
(اiii) (أحمد بن سالم العامرى : القيادية التحويلية فى المؤسسات العامة : دراسة

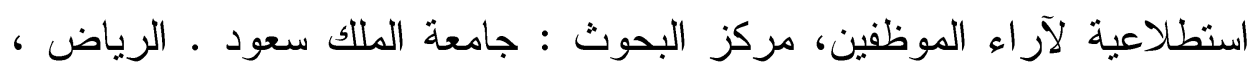
. r...

(") سبد الهو ارى : القائد التحويلى ـ للعبور بالمنظمات للقرن اب ، القاهرة : مكتبة

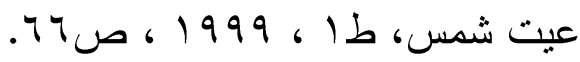

(")عباس عبد مهدى الثريفى ، منال محمود محمد التتح ، درجة ممارسة مديرى

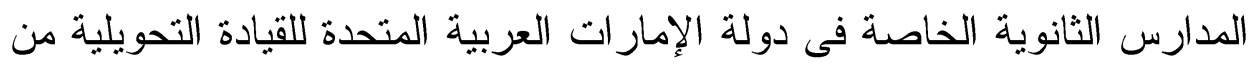

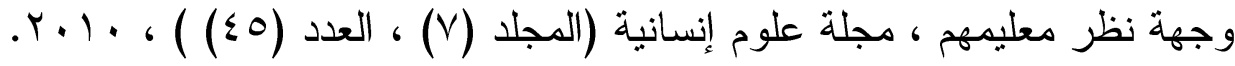
() حسن يونس غرابية ، درجة ممارسة المشرفين التربويين لسلوك القيادة التحويلية و علاقتها بمستوى آدائهر ، رسالة دكتور داه غير منشورة ، جامعة داندة عمان العربية

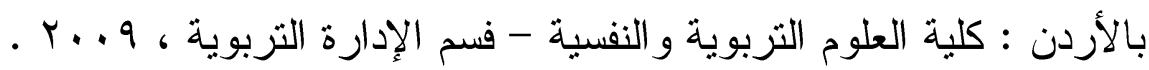
(") سناء محمد عيسى ، دور القيادة التحويلية فى تطوير أداء مديرى الدارس الثانوية فى محافظات غزة ، رسالة ماجيستير غير منشورة ، الجامعة الإسلادية

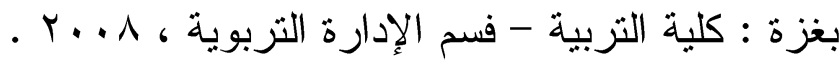


(انياد (المومنة ، الطحاينة ، السلوك القيادى التحويلى لدى عمداء كليات التربية

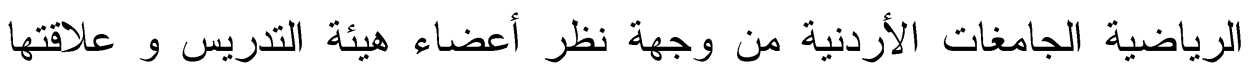

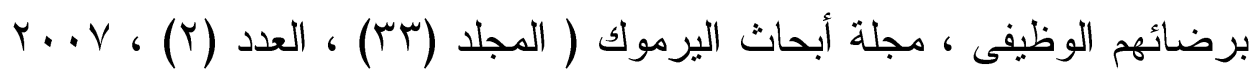

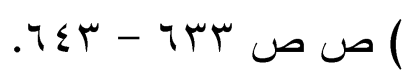

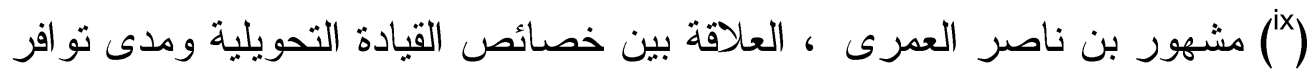

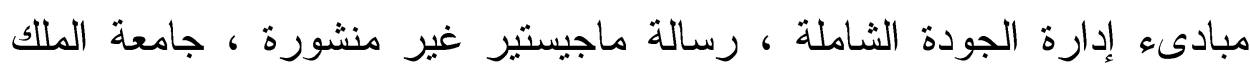

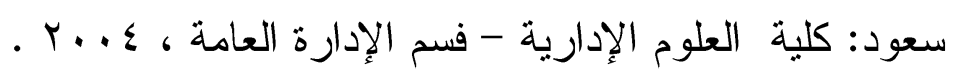

) Lucks H. J.: Transformational Leadership Through Amyers $-x$ ( Briggs Analysis: Personality Styles Of Principals And Teachers At The Secondary Level . Dissertation Abstract International , A62/11, 2002, p.3642 .

(") نادية بنت عبد الله بنت أحمد ، منطلبات تطبيق إدارة المعرفة فى جامعة السلطان قابوس : دراسة ميدانية ، رسالة ماجيستير غير منشورة ، جامعة السلطان

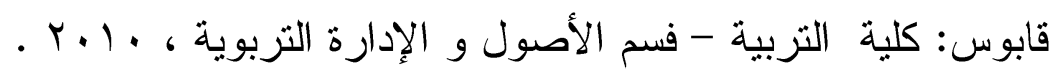
(أحمد الخطيب وآخرون : تقويم مدى فعالية برنامج الإدارة العليا للقيادات (xii)

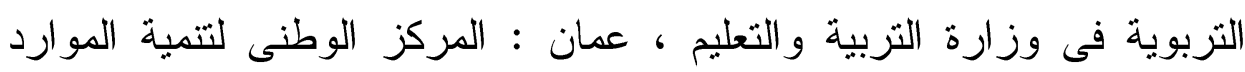

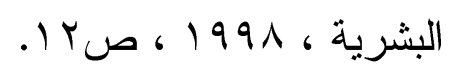

) Cheung M. and Wong, C..Transformational leadership, xiii( leader support and employee creativity, leadership and Organization Development Journal, 32(1). , 2010, p.657 .

) Sani, Achmad \& Maharani, Vivin , The impacts of xiv( Transformational Leadership and Organizational Commitment on Job Performance with the among Lecturers of faculty in the 
Islamic maulanamalikibrahimmalang university: the mediating effects of Organizational Citizenship Behavior, International , Journal of Academic Research, Vol. 4. No.4, 2012 , p.102 . (xv (حسان دهش جلاب : ادارة السلوك التظظيمي في عصر التغيير، عمان: دار

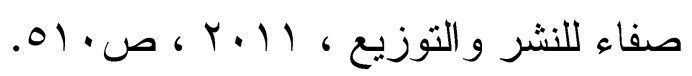

) Bass, B.M.,\& Avolio ,B.J., Multifactor-Leadership-xvi( Questionnaire: Manual and Sampler Set (3rd ed.). Redwood City, CA: Mind Garden, Inc.behavior", New York , Oxford university Press., 2004 , p.3642 .

,fu-giu,et,al,Effect-of-Leadership-Style-on- ) Wangxvii( Organization Performance as Viewed From Human Resource Management Strategy Africa, Journal of Business Management, Vol 4. No 18. 2010., p.2925 .

) Shibru , Bekele, \& Darshan , G.M , "Transformational xviii( Leadership and its Relationship With Subordinate Satisfaction with the Leader (The Case of Leather Industry in Ethiopia) " Interdiscipilinary Journal of contemporary research in Business, Vol 3. No. 5 . , 2011, p.687 .

) Belle ,Nicola (2013)," Leading to Make a Difference: A xix( Field Experiment on the Performance Effects of Transformational Leadership, Perceived Social Impact and Public Service Motivation" , Paper presented at the 11th 
Public Management Research Conference ,Madison, Wisconsin , 2013 , p.2 .

( ) فاضل حمد القيسي و ،علي حسون الطائي : الادارة الاستر اتيجية (نظريات-

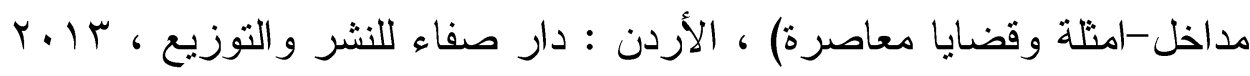

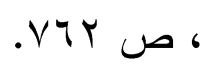

(1) محمد رحمة فنجان السودانى: تمكين وابداع المرؤوسين في اطار انموذج

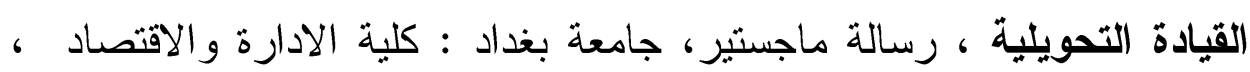

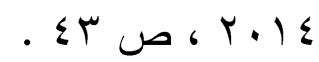

) Niekerk , Magdalena, Maria,Van:2005"Transformational xxii( Leadership at a Higher Education Institution", Master of arts, University of South Africa. , 2005 , p.5 .

( سعيد بن محمد الغامدي : القيادة التحويلية في الجامعات السعودية: مدى

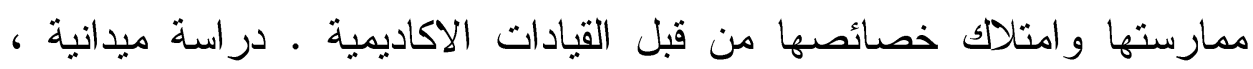

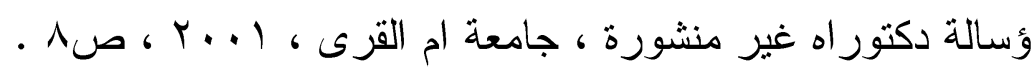

Goodwin , Vicki L. \& Whittington , J. Lee \& Murray , ) xxiv( Brian, Moderator or Mediator, Examining the Role of Trust in the Transformational Leadership Paradigm , Journal of Managerial Issues, Vol. XXIII Number 4 ., 2011 , p.411 .. ( ) حافظ عبدالكريم الغزالي : اثر القيادة التحويلية على فاعلية عملية اتخاذ القرار ، رسالة ماجستير غير منشورة ، جامعة الشرق الاوسط : كلية الاعمال ،

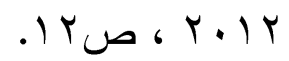


) Al- Swidi , Abdullah Kaid \& Nawawi, Mohd Kamal Mohd\&xxvi( Al-Hosam , Asma, Is the Relationship between Employees' Psychological Empowerment and Employees' 76-Job Satisfaction Contingent on the Transformational Leadership? A Study on the Yemeni Islamic Banks, Asian Social Science , p p.126-137 Vol. 8, No. 10.2012

) Ismail, A., Mohamad ,M., Mohamed, H., Rafiuddin ,N., Peixxvii( Zhen ,K., "Transformational And Transactional Leadership Styles", Theoretical And Applied Economics, Volume Xvi), No.

$$
\begin{aligned}
& \text { 6(547). , } 2010 \text {, p.69 } . \\
& \text { (Xviii) }
\end{aligned}
$$

(إبر اهيم الخلوف الملكاوى : إدارة المعرفة : الممارسات و التفاصيل ، (xxix

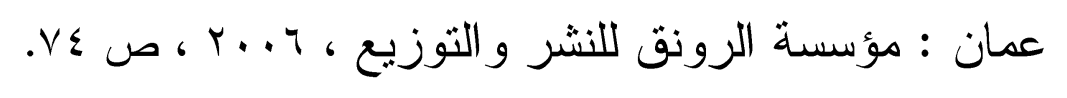

( حسنى عبد الرحمن الثيمى : إدارة المعرفة : الرأسمعرفية بديلا ، القاهرة :

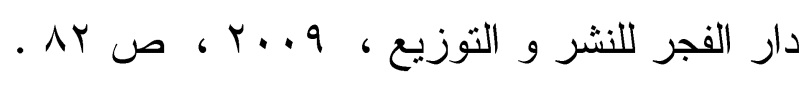

(xxi

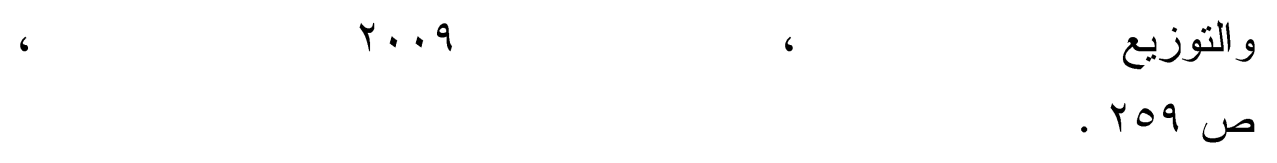

(xxii

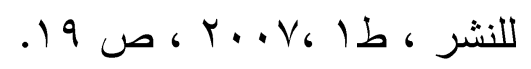

(xxxii)

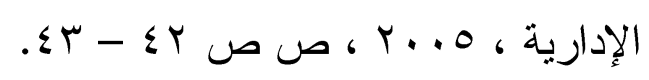

roN 


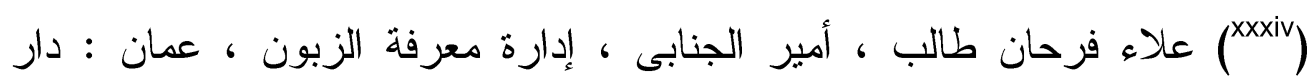

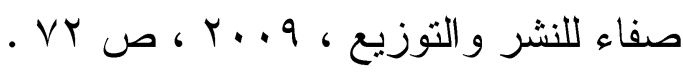

(

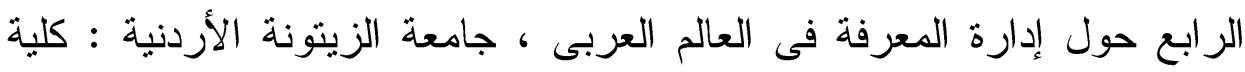

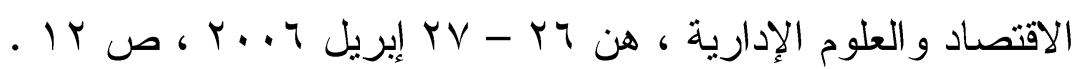

) Leavitt, Paige. "Using knowledge management to drive xxxvi( innovation." American Productivity \& Quality Center, APOC,

$$
2003, \text { p.17. }
$$

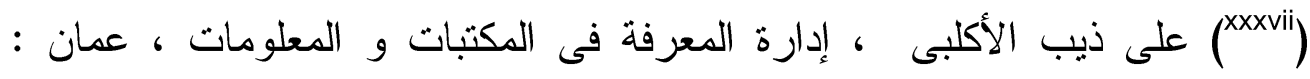

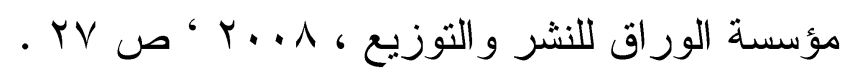

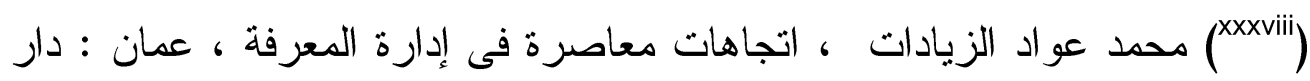

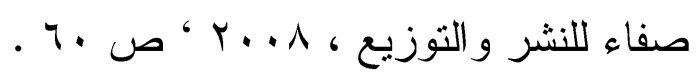

), Grover, V., and Davenport, T., General Perspectives on xxxix( Knowledge Management, Journal of Management Information System, vol. 18, no. 1, 2001, pp. 12-21.

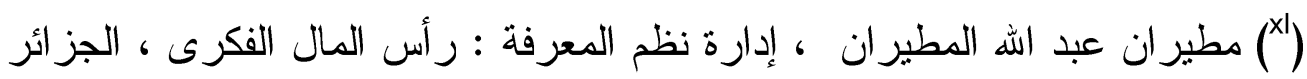

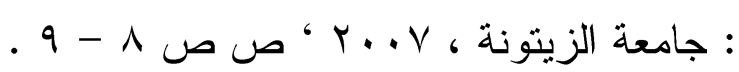

, Elayne, "Knowledge Management: Current Issues Coakes )xli( and Challenges", U.S.A., Idea Group Publishing. 2003 , p.97

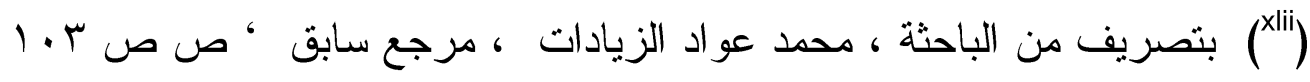
$.1 \cdot \varepsilon-$ 
( ) مطير ان عبد اله المطيران ، مرجع سابق ، ص (Vliii) (x) سمير عبد الوهاب ، منطلبات تطبيق إدارة المعرفة فى المدن العربية : دراسة

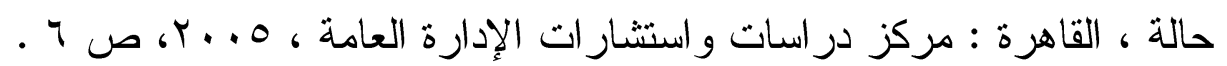

$$
\text { سمير عبد الوهاب ، مرجع سابق ، ص } 1 \text { (xlv }
$$

(lvi)

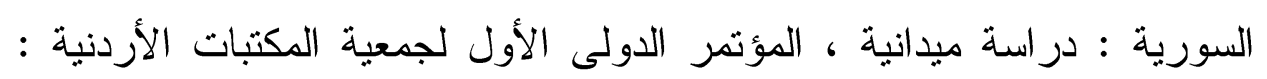

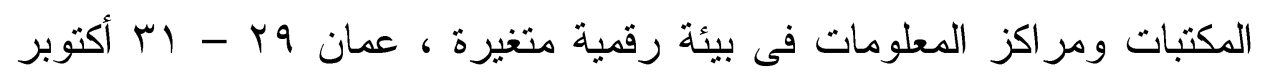

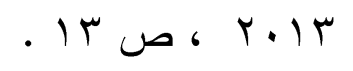

(xlvii)

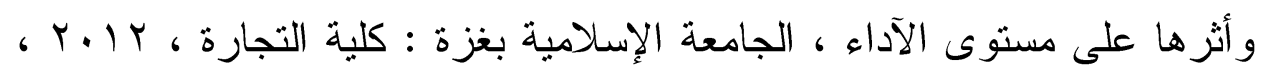

$$
\begin{aligned}
& \text { ص } 01.0 \\
& \text { ياسر الصاوي، مرجع سابق ، ص ص لT (Xliii) }
\end{aligned}
$$

زيدان عبد الباقى، قواعد البحث الاجتماعى. القاهرة: مطبعة السعادة، طس،

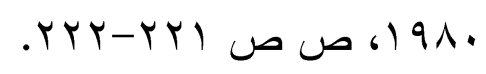

(ا) عدلى على أبو طاحون، دناهج وإجراءات البحث الاجتماعى: الإطار الفلسفى

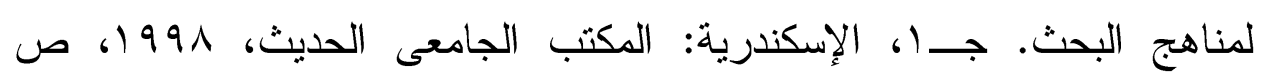
rV

(li)

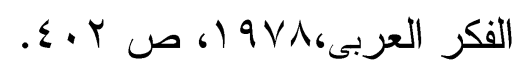

